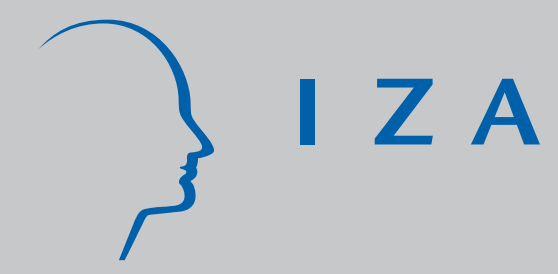

IZA DP No. 416

Employed 40 Hours or Not-Employed 39:

Lessons from the 1982 Mandatory Reduction of the Workweek

Bruno Crépon

Francis Kramarz

J anuary 2002 


\title{
Employed 40 Hours or Not-Employed 39: Lessons from the 1982 Mandatory Reduction of the Workweek
}

\author{
Bruno Crépon \\ INSEE-CREST
}

\section{Francis Kramarz}

CREST-INSEE, Paris, CEPR, London and IZA, Bonn

\author{
Discussion Paper No. 416 \\ January 2002
}

\author{
IZA \\ P.O. Box 7240 \\ D-53072 Bonn \\ Germany \\ Tel.: +49-228-3894-0 \\ Fax: +49-228-3894-210 \\ Email: iza@iza.org
}

This Discussion Paper is issued within the framework of IZA's research area Evaluation of Labor Market Policies and Projects. Any opinions expressed here are those of the author(s) and not those of the institute. Research disseminated by IZA may include views on policy, but the institute itself takes no institutional policy positions.

The Institute for the Study of Labor (IZA) in Bonn is a local and virtual international research center and a place of communication between science, politics and business. IZA is an independent, nonprofit limited liability company (Gesellschaft mit beschränkter Haftung) supported by the Deutsche Post AG. The center is associated with the University of Bonn and offers a stimulating research environment through its research networks, research support, and visitors and doctoral programs. IZA engages in (i) original and internationally competitive research in all fields of labor economics, (ii) development of policy concepts, and (iii) dissemination of research results and concepts to the interested public. The current research program deals with (1) mobility and flexibility of labor, (2) internationalization of labor markets, (3) the welfare state and labor markets, (4) labor markets in transition countries, (5) the future of labor, (6) evaluation of labor market policies and projects and (7) general labor economics.

IZA Discussion Papers often represent preliminary work and are circulated to encourage discussion. Citation of such a paper should account for its provisional character. 


\section{ABSTRACT \\ Employed 40 Hours or Not-Employed 39: Lessons from the 1982 Mandatory Reduction of the Workweek*}

We use longitudinal individual wage, hours, and employment data to investigate the effect of the February 1, 1982 mandatory reduction of weekly working hours in France. Just after François Mitterrand's election in May 1981, the government decided to increase the minimum wage by $5 \%$. Then, as promised in its electoral program, the socialist government reduced the workweek from 40 to 39 hours. At the same time, it mandated stable monthly earnings for minimum wage workers and recommended the stabilization of monthly earnings for other workers (recommendations followed by $90 \%$ of the firms). We show that workers directly affected by these changes-those working 40 hours in March 1981 as well as those working overtime at the same date -were more likely to lose their jobs between 1981 and 1982 than workers not affected by the changes-those working 36 to 39 hours in March 1981. Moreover, because the decree enforcing the new standard was issued faster than earlier promises, some firms had no time to complete negotiations and their workers were still working 40 hours after February 1, 1982. We show that these workers were also strongly affected by the reduction in standard hours. Our estimates of the impact of this one-hour reduction of the workweek on employment losses vary between $2 \%$ and $4 \%$, depending on the methodology or the data used. Furthermore, we show that minimum wage workers were most affected by the changes. This result, consistent with our model, is due to the impossibility of adjusting their monthly wage, which results in excess job destruction and creation. These results should help us understand the possible effects of the upcoming mandatory reduction of hours in France, where the maximum weekly working hours declined from 39 to 35 hours beginning in January 2000. Similar programs are envisaged in other European countries, which hope that hours reductions will be an efficient policy for reducing unemployment.

JEL Classification: J31, J23

Keywords: Hours reduction, wages, unemployment

Francis Kramarz

CREST-INSEE

Département de la Recherche

15, bd Gabriel Péri

92245 Malakoff

France

Tel.: +33141176033

Fax: +33 141176046

kramarz@ensae.fr

\footnotetext{
* We would like to thank the Editor of this Journal, Sherwin Rosen, an anonymous referee for their extremely helpful suggestions as well as John Abowd, Alain Chenu, Pierre-André Chiappori, Guy Laroque, Françoise Maurel, Bernard Salanié, and Béatrice Sedillot for their remarks on a previous version of this text and Stuart Basefsky for providing useful information and, above all, Jean-David Fermanian for finding an error in the construction of the data used in a former analysis. All remaining errors are ours.
} 


\section{Introduction}

In 1998 the French government adopted a policy requiring firms to implement a 35-hour workweek by the year 2000. ${ }^{1}$ Today, most French firms have negotiated a workweek reduction agreement with their unions or personnel delegates and have implemented it. Employer confederations claim that the reduction has had an adverse impact on their activity, in particular by creating short-term labor shortages in a booming period together with an increase of production costs. The representatives of small firms are pessimistic about the upcoming introduction of the mandatory reduction in 2002. On the other hand, this policy appears to be popular among unions and a fairly large part of the French working population. It is even considered successful by some politicians because of the sharp decrease in unemployment during the last three years. Some Italian and Spanish union leaders and politicians advocate the same set of policies as the French have adopted (Economist, 1998a and 1998b). Germany's newly elected government also appears to support mandatory hours reductions, as shown in the famous BMW agreement (Economist, 1999, 1998c).

Although the media are full of discussions of the effects of the hours-reduction laws, serious evaluation of the economic impact of the recent workweek reduction is difficult, even impossible, because the changes are too recent. Indeed, there are very few empirical assessments of the effects of this type of regulation, leaving the debate open to views based on political prejudices (see, however, Hunt, 1999, who mostly focuses on the German case). This is ironic because France has already attempted to manipulate working hours in order to reduce unemployment. In 1982, a few months after François Mitterrand's election, the socialist government, as stated in its election platform, decided to shorten the workweek by cutting the maximum legal number of hours per week. $^{2}$ It is fair to say that the election of François Mitterrand was not foreseen by most political analysts. At the beginning of 1981, the Paris correspondent of the Economist wrote: "For months

\footnotetext{
${ }^{1} 2002$ for firms with 20 employees or less.

${ }^{2}$ The legal workweek in France is determined by the maximum number of hours, as specified in national statutes and implemented in collective bargaining agreements. The firms are permitted to employ workers for more than the national statutory maximum hours under the following conditions: (1) overtime hours up to a statutory limit at a negotiated wage premium, (2) in certain sectors, e.g. hotels and restaurants, the statutory limits are higher, (2) management and certain engineering positions (cadre) specified in the collective bargaining agreement are exempted. About 95\% of the jobs in France are covered by collective bargaining agreements even though a much smaller percentage of workers belong to unions (Card, Kramarz, and Lemieux, 1999).
} 
French opinion polls have made President Giscard d'Estaing's reelection this spring seem a foregone conclusion." (Economist, 1981). Furthermore, the victory of the socialists at the parliamentary elections, which took place a few weeks after the presidential election, was an even longer shot in those first months of 1981. Therefore, even though the hours reduction was included in the socialist's platform, it was almost fully unexpected 6 months before the elections. The hours reduction took place at the beginning of 1982, in February, a few months after the 5\% increase in the French minimum wage, the SMIC, of July 1981. In addition, the February 1982 decree stipulated the mandatory rigidity of monthly earnings for minimum wage workers employed by the firm at that date.

In this article we investigate the effects of this reduction in the maximum workweek. We evaluate the effect of the workweek reduction on employment to non-employment transitions using two different approaches, based on two natural experiments associated with the 1982 hours reduction. In the first one, we compare workers who worked 36 to 39 hours before 1982 with workers who worked exactly 40 hours and with those who worked overtime (up to 48 hours). In the second experiment, we take advantage of specific features of the implementation process of the reduction. As mentioned earlier, some firms were surprised by the February 1, 1982 decree. In April 1982, the date at which the French Labor Force Survey took place, a sizeable share of firms had not altered their hours to the new standard. To analyze these two issues, we use panel data from the French Labor Force Survey (Enquête Emploi) for the period going from 1977 to 1987. Our results show that workers who were working exactly 40 hours per week in March 1981 as well as workers who were working overtime (41 to 48 hours) per week in March 1981 were less likely to be employed in 1982 than observationally identical workers who, in 1981, were working 36 to 39 hours per week. This first analysis uses differences in differences techniques by comparing transitions from 1981 to 1982, after implementation of the decree with those prevailing between 1978 and 1981, before the election of François Mitterrand. Our second analysis also demonstrates that workers still employed 40 hours in 1982 lost their jobs more often than those already employed under the new standard workweek. Indeed, all our results show that these job losses can be directly attributed to the reduction in the workweek. In our first analysis, the effects are significant and vary between $2.6 \%$ and $3.9 \%$ according to the technique considered. In our second analysis, the effects are also quite significant, and we estimate a lower bound for the induced additional job losses at $4.1 \%$. Furthermore, we show 
that minimum wage workers were much more affected than others. All such results are fully consistent with predictions of most theoretical models of hours reduction, in particular since wage rigidity was binding for most low-wage workers, particularly after the 5\% minimum wage increase of July 1981. In particular, this wage rigidity should have generated simultaneous job destruction and creation. Given empirical relationships between employment destruction and worker flows (Abowd, Corbel, and Kramarz, 1999), excess job destruction that is observed for low-wage workers, around $8 \%$, corresponds to roughly $2 \%$ annual employment destruction, yielding an elasticity of employment to labor costs just below minus one, in the same ballpark as other estimates for this category (Abowd, Kramarz, Margolis, and Philippon, 2000 and Kramarz and Philippon, forthcoming). In addition, our results show, also in conformity with the model, that better compensated workers were less directly affected by the reduction of the workweek.

In the next section, we present the decree and the institutional context surrounding the 1982 reduction of the workweek. We briefly discuss the likely effects of this reduction in Section 3. Section 4 contains a description of the data sets that are used in the analysis. In Section 5, we present our analysis of the direct natural experiment whereas the analysis of the delayed reduction of hours is examined in Section 6. Finally, we conclude in section 7.

\section{Institutional Context}

\subsection{Principles and Legal Aspects of the 1982 Reduction of the Workweek}

\subsubsection{Changes in Hours}

The number of hours worked strongly decreased during the seventies, from 48 hours in 1974 to just above 40 hours in 1981 (see also Table 1). During all this period, indeed since 1936, the standard workweek was 40 hours. François Mitterrand's election in May 1981 induced a sudden decrease of the standard to 39 hours (January 16, 1982 ordinance). In fact, negotiations started just after May 1981, since the reduction was part of the left's electoral platform. These negotiations were should have ended before 1982. In a report to the President at the end of 1981, the Prime Minister mentions that negotiations did not make real advances but nevertheless recommends letting firms' and workers' unions and delegates continue until the second quarter of 1982, the suggested date of application of the new standard. Against his Prime Minister's recommendations, François Mitterrand imposed, by the January 16 ordinance, the new 39 hours standard, which took effect February 1, 
1982. Collective agreements, specifying the terms of application of the decree, ensued, starting with the largest firms in the manufacturing industries and spreading to smaller firms and other industries (Marchand, Rault, and Turpin, 1983).

Therefore, the law reducing the workweek became effective February 1, 1982. It mandated a maximum legal workweek of 39 hours, whereas it was 40 hours previously, and only slightly altered the prevailing regulation on overtime: the overtime premium remained $25 \%$ for the first four hours, and 50\% above, but the maximum compensated hours was reduced from 50 to 48 per week (for more details see Marchand, Rault, and Turpin, 1983).

\subsubsection{The Mandatory Nominal Wage Rigidity and its Consequences}

The government also recommended that monthly pay after the change in workweek remain unchanged for all workers, but no special arrangements were included in the law to enforce this recommendation except for workers paid the legal minimum wage (SMIC) and working 40 hours. For these workers, a special hourly minimum wage was prescribed in order to guarantee that their monthly earnings be unchanged after the change in hours. ${ }^{3}$ Hence, a worker paid the SMIC and working 40 hours before February 1, 1982 received the same monthly earnings after February $1^{\text {st }}$ even though the workweek was only 39 hours. However, any worker hired at the minimum wage rate after February 1, 1982 received monthly pay corresponding to his or her exact number of hours. Therefore, newly hired workers were approximately 2.5\% (100 Francs a month or \$20 US) cheaper than their more senior counterparts because of this special provision in the hours-reduction law. Furthermore, since a 5\% increase in the hourly SMIC was one of the first decisions made by the newly elected government in mid-1981, the hourly cost of minimum wage workers increased by 7.5\% between mid-1981 and mid-1982. Finally, for all other categories of workers, the "recommendation" to leave monthly pay unchanged seems to have been followed by most firms. A survey conducted in September 1982 showed that more than $90 \%$ of all workers had their monthly pay unchanged after implementation of the law reducing the length of the workweek (Marchand, Rault, and Turpin, 1983). ${ }^{4}$

\footnotetext{
${ }^{3}$ The minimum wage legislation in France specifies an hourly wage.

${ }^{4}$ Manipulations of the compensation package similar to those described in Trejo (1991) were ruled out.
} 


\section{Theory and Identification of the Impact of the Workweek Reduction}

\subsection{Theory}

The theoretical consequences of changes in standard hours are now well known (see Rosen, 1968, Ehrenberg, 1971, and Calmfors and Hoel, 1988 among many others). Consider a firm that produces with a production function $f(h, l, k)$ where $h$ are weekly hours, where $l$ denotes total employment, and where $k$ denotes capital. The firm faces a cost function that comprises wages $(w$ denotes the hourly wage, $\theta$ denotes the overtime premium for all hours above $h_{s}$ the mandated standard hours), a fixed cost of employment $f$ (see Rosen, 1968), and a cost of capital $r$.

In this framework, usual results based on marginal costs considerations as developed in Rosen (1968) and, more fully, in Calmfors and Hoel (1989) hold (see also Hunt, 1999). They can be summarized as follows. First, consider the case in which firms minimize costs with output fixed. The effect of a reduction in the normal working time depends on the initial situation. Obviously, there is no effect if the firm has optimal hours below the old standard. At the opposite extreme, if the initial situation is one with overtime, then employment decreases and hours increase. Indeed, the marginal cost of hiring is increased when standard hours decrease whereas the marginal cost of additional overtime does not change. Furthermore, the marginal cost of a separation decreases when standard hours decrease. Finally, assuming again that output is fixed, if the firm moves from the old standard to the new standard, employment unambiguously increases whereas when the firm moves from the old standard to an interior solution with overtime, employment may decrease or increase.

Next, assume that firms maximize profit instead of minimizing costs, a negative output effect arises when standard hours are reduced. This effect is larger, the larger the absolute value of the elasticity of demand for workers (Calmfors and Hoel, id. page 57). Hence, the likelihood of positive employment effects is smaller than when output is fixed. In fact, increasing employment may even be impossible.

Now, to understand the specifics of the French workweek reduction, we must remember that nominal monthly wage rigidity was mandated for workers employed at the date of the decree. It is therefore useful to have two periods in our model; one that precedes the reduction in the workweek ( $d=0$ and before); one that is at, and follows, the reduction of the workweek $(d=1)$. In period 0 , we have: 
$C_{0}=w_{0} h_{0} l_{0}+w_{0} \theta\left(h_{0}-h_{s, 0}\right) l_{0}+f l_{0}+r k_{0}$

with

$l_{0}=(1-q) l_{-1}+e_{0}-s_{0}$

where $l_{-l}$ denotes employment at the previous date, $q$ denotes the exogenous quit rate, $e$ denotes the number of hires in the firm, and $s$ denotes the number of separations (i.e. excluding quits) when we assume that firms choose hours in excess of standard hours. Total costs are:

$C_{0}=w_{0} h_{0} l_{0}+f l_{0}+r k_{0}$

when optimal hours are set at the standard. The firm optimizes on capital, hours, hires, and separations. Importantly, since hires and separations both entail a cost, as only the difference between hires and separations matters for production through employment, it is never optimal to hire and fire simultaneously. Hence, at least one of $e$ or $s$ is equal to zero. ${ }^{5}$

Consider what happened after the French reform of 1982. First, standard hours, $h_{s, 1}$, decreased. Second, monthly wages did not decrease (by law for minimum wage workers whereas it was only suggested for other workers but firms followed the suggestion). Hence, hourly pay increased for those who were already employed in the firm while hourly pay was left unchanged for new hires. Two wage rates prevailed at those dates for otherwise identical workers. Therefore, in period 1, the cost function that the firm faces is:

$$
\begin{gathered}
C_{1}=w_{1}^{1} h_{1} e_{1}+w_{1}^{1} \theta\left(h_{1}-h_{s, 1}\right) e_{1}+w_{0}^{1} h_{1}\left[(1-q) l_{0}-s_{1}\right]+ \\
w_{0}^{1} \theta\left(h_{1}-h_{s, 1}\right)\left[(1-q) l_{0}-s_{1}\right]+f l_{1}+r k_{1}
\end{gathered}
$$

with $l_{1}=(1-q) l_{0}+e_{1}-s_{1}$ and where $w_{1}^{1}$ denotes the wage of the new hires, and where $w_{0}^{1}$ denotes the wage of the workers that were present in the firm before period 1 . The equivalent equation can be written when hours are set at the new standard. Because of the legal restrictions and the "suggestions" to the firms, the following equation holds:

$$
w_{0}^{1} h_{s, 1}=w_{0} h_{s, 0} \text { or } w_{0}^{1}=w_{0} \frac{h_{s, 0}}{h_{s, 1}}>w_{0} \text { and } w_{1}^{1}=w_{0}
$$

It is straightforward to see that this double wage structure exacerbates the negative employment effects of hours reduction found in usual models discussed above.

5 The proof is straightforward. One must write the lagrangean with the multipliers for $e_{0} \geq 0, s_{0} \geq 0$ and look at the first-order conditions for hires and separations. 
There are also dramatic consequences for worker flows. In addition to the (negative) effects on employment that we have just presented, the French specifics of the 1982 change add another source of employment loss: it is often optimal for firms to separate workers constrained by the old standard, i.e. workers paid 40 hours for a 39-hours workweek, and to hire new workers unconstrained by the old standard, i.e. workers who will be paid 39 hours for a 39-hours workweek (see Crépon and Kramarz, 2000, Appendix 1).

\subsection{Two Sources of Identification}

The process of reduction of the standard workweek from 40 to 39 hours was sudden, unexpected but, at the same time, took several years. In April 1982, the month in which the 1982 French Labor Force Survey took place, only a fraction of the firms had signed an agreement with their workers. The structure of hours in some firms in 1982 was identical to its structure before promulgation of the decree. Indeed, Table 4 shows that the fraction of individuals employed 40 hours in the population of workers employed 40 or 39 hours was equal to $28 \%$ in 1982 and fell to approximately $20 \%$ in 1983, 1984, and 1985. Hence, the passage to the new standard continued, even after April 1982, date of the survey. In addition, negotiations resulted in new and old workweeks of equal lengths for $20 \%$ of the workforce; one hour being counted as overtime after February 1, 1982.

These two characteristics of the process constitute our two sources of identification of the effects of the hours reduction. The reduction of the workweek was unexpected. In addition, some full-time workers were already employed 39 hours or less in 1981. Hence, it can be considered as a natural experiment. We evaluate the effect of the reduction of the workweek by comparing the employment transitions of workers employed 40 hours in 1981 with those of workers employed less than 40 hours at the same date. The identifying restriction is then that workers employed between 36 and 39 hours in 1981 are not affected by the reduction. Since most theoretical analyses also predict a negative impact on overtime workers, we also examine the employment transitions of workers employed 41 to 43 hours, exactly 44 hours (the kink in the overtime premium schedule), and 45 to 48 hours (the overtime premium jumps from $25 \%$ to $50 \%$ for all hours in excess of 44 ) in 1981, once again comparing them with those of the workers employed less than 40 hours at the same date.

The reduction of the workweek was also gradual, and this constitutes another source of identification. To see this, assume that, once the reduction has been negotiated with a group of 
workers, all such workers are employed 39 hours exactly. Hence, all those who work 40 hours in 1982 are potentially affected by the forthcoming reduction while all workers employed 39 hours at that date are not any more. Therefore, this last group is a potentially valid control group.

\section{The French Labor Force Survey}

In this section, we describe the longitudinal data sets, the French Labor Force Surveys (called the Enquête Emploi), that are used in the analysis. Our analysis uses data from 1977 to $1987 .{ }^{6}$ Since the French Labor Force Survey (LFS, hereafter) questionnaire and survey structure changed between 1981 and 1982, we first describe the features of the survey that are common to the two sub-periods, then we describe the specifics for the years 1977 to 1981, and finally, we describe the LFS for the period 1982 to 1987.

Every year, approximately 60,000 domiciles are sampled from the stock of all houses and apartments (the sampling rate is exactly 1/300). In March of the survey year, each person in the sampled household is interviewed (in person if present at the time of the interview or by proxy if absent). $^{7}$ One third of the domicile sample is replaced each year. Hence, all persons in the household are followed at most three times. We build our longitudinal data using this feature. In all years, most of the usual household and individual characteristics are available for all surveyed individuals. Sex, education categories (6 categories), age at the end of schooling (from which we derive labor force experience), region (lives in Ile de France or not), employment contract type (apprentice, short-term contract, other) and status (employed or not employed), an indicator for part-time status, seniority, employer's industry (14 categories), employer's size (4 categories) are available in all years and are used in most of our analyses. The employment status of the individuals is defined according to the ILO criteria.

During the first sub-period (1976 to 1981), two features are essential to note. First, there is no wage variable in the data. Second, the information is not on "usual" hours but on hours worked during the reference week. If the individual works fewer than 45 hours, a second question is asked on possible reasons. Some are labeled temporary (strike, disease, etc.) whereas others are labeled durable,

\footnotetext{
${ }^{6}$ For some descriptive statistics, we use data from 1976 onwards.

${ }^{7}$ In 1979, 1980, and 1981, the LFS also took place in October. Each wave had the same size as those of March. Unfortunately, the October survey does not exist after 1981 and is therefore not usable for
} 
among which are distinguished part-time work and usual duration of the workweek. Hence, we have a potential way of approximating the "usual hours" concept. Unfortunately, responses to this second question appear to be frequently missing and this possible measure is not usable.

Starting in 1982, monthly wages (grouped by cells of 500 French Francs, roughly \$100 US) and usual weekly hours are also available. Although the usual survey date is March, because of the 1982 Census of Population, the 1982 Labor Force Survey took place in April of that year. Hence, the 1982 Labor Force Survey took place just after the legal reduction in the workweek to 39 hours took effect on February 1, 1982.

For our first analysis, we construct four three-year panel data sets in which individuals are followed from 1977 to 1979 , from 1978 to 1980 , from 1979 to 1981 , and from 1980 to 1982. This allows us to characterize workers' situations before, at, and just after implementation of the legal change in the standard workweek.

For our second analysis, we construct also four three-year panel data sets in which individuals are followed from 1982 to 1984, from 1983 to 1985, from 1984 to 1986, and from 1985 to 1987. This allows us to understand the implementation process of the reduced workweek that took place in 1982 and just after, and contrast this period with the ones immediately after.

\section{The Reduction of the Workweek: a Natural Experiment}

\subsection{Principle and Descriptive Analysis}

Table 1 shows the proportion of full-time workers employed 36 to 39 hours within the population of all full-time workers employed 36 to 48 hours in 1981. This fraction is small, 2.4\%, but is increasing across time. The fraction of workers employed 40 hours is also increasing whereas the fraction of overtime workers constantly decreases between 1976 and 1981. Furthermore, the number of observations also increases during the period, reflecting a decrease in the number of workers employed more than 48 hours. Table 2 shows the employment to non-employment transition rates for these various categories of workers. Between 1981 and 1982, employment to non-employment transitions are more intense for workers employed 40 hours than for those employed 36 to 39 hours.

our purpose. 
$6.2 \%$ of all workers employed 40 hours in 1981 have no employment in 1982 whereas $3.2 \%$ of those employed less than 40 hours are in the same situation, a difference of three percentage points. However, the size of the control group that we use to evaluate the impact of the reduction of the workweek is small; $2.4 \%$ of the workers with hours between 36 and 48 were employed less than 40 hours in March 1981.

\subsection{Selectivity Bias}

\subsubsection{Motivation and Statistical Model}

We now discuss the identification conditions under which we can isolate a causal effect of the workweek reduction on employment. Two hypotheses are necessary for our analysis. First, workers employed 36 to 39 hours must not have been affected by the reduction of the workweek. Second, the employment to non-employment transitions of these workers identifies what the transitions of workers employed 40 hours or more would have been in the absence of a reduction of the workweek. Therefore, we classify individuals in two categories: those affected (1) and those notaffected (0) by the reduction. We consider the two corresponding labor market situations $N E(0)$, $N E(1)$ equal to 1 if the individual is not-employed and equal to zero otherwise. The effective situation of any individual is:

$$
N E_{i}=N E_{i}(0)+D_{i}\left[N E_{i}(1)-N E_{i}(0)\right]
$$

where $D$ is equal to 1 if the individual is employed 40 hours or more hours a week in 1981 . The employment loss probability is $E\left(N E_{i}\right)$ (where $E($.$) denotes the expectation of the random variable$ between parentheses). We focus on the quantity $N E_{i}(1)-N E_{i}(0)$. Such quantities measure, for each individual, the difference between the labor market outcome when affected by the reduction of the workweek with what would have been the outcome if they had not been affected by this reduction. We follow Rubin (1974) in his definition of a causal effect. These quantities, different for different individuals, are unobservable since any given individual is in one and exactly one state among the two possible ones. Only some parameters of the distribution of $N E_{i}(1)-N E_{i}(0)$ can be identified, under some hypotheses. For instance, one can identify the expectation of the effect, conditional on changing hours from 40 to 39 (average treatment on the treated in Heckman, Lalonde, and Smith, 1999, terminology), defined as $E\left(N E_{i}(1)-N E_{i}(0) \mid D_{i}=1\right)$. To measure this last quantity, we assume $\left(\mathrm{H}_{0 \mathrm{~A}}\right)$ that, conditional on observable variables, the potential outcome, in which workers are not affected 
by the reduction, $N E_{i}(0)$, is independent of actually being affected by the reduction to 39 hours (independence conditional on observable variables, Rubin, 1977). The corresponding equation is:

$$
H_{0 A}: E\left(N E_{i}(0) \mid x_{i}, D_{i}=1\right)=E\left(N E_{i}(0) \mid x_{i}, D_{i}=0\right)
$$

Therefore, the following relation holds:

$$
\begin{aligned}
E\left(N E_{i} \mid x_{i}, D_{i}\right) & =E\left(N E_{i}(0) \mid x_{i}\right)+D_{i} E\left[N E_{i}(1)-N E_{i}(0) \mid x_{i}, D_{i}=1\right] \\
& =g_{0}\left(x_{i}\right)+D_{i} e_{D}\left(x_{i}\right)
\end{aligned}
$$

where the function $e_{D}\left(x_{i}\right)$ represents the average effect of the workweek reduction when applied to individuals with characteristics $x_{i}$.

There are several available methods for estimating the effect of the workweek reduction that are compatible with the above hypotheses. A simple and transparent method is based on the differences in the employment to non-employment transition rates between workers affected and not affected by the change of the standard workweek, controlling for all their observable characteristics. To analyze the 1982 employment losses of individuals employed in 1981 with observable characteristics $x_{81}$, we estimate a regression using a linear probability model based on the following relation:

$$
E\left[N E_{82} \mid x_{81}, D_{81}\right]=x_{81} \beta+\alpha_{81} \mathrm{I}\left(D_{81}=40\right)
$$

where the $i$ index has been omitted for simplicity and where $N E_{82}$ corresponds to the nonemployment situation in 1982. The impact of the workweek reduction on employment to nonemployment transitions is given by the coefficient $\alpha_{81}$. Note that other techniques, such as matching methods (Heckman, Ichimura, and Todd, 1998) could have been used. We selected a linear probability model for simplicity and transparency.

To include workers working overtime hours, Rubin's model can be extended using the framework with multiple treatments as it was recently developed in Imbens (1999), Lechner (1999), and Brodaty, Crépon, and Fougère (1999). In 1981, before the change in the standard workweek, the overtime premium was $25 \%$ for all hours between 41 and 44 and $50 \%$ for all hours strictly above 44. Hence, because of the structure of the overtime premium schedule, in addition to workers employed 40 hours, we distinguish among workers employed 41 to 43 hours, workers employed exactly 44 hours (for whom the marginal cost of employment increases the most when the standard workweek is reduced by one hour), and workers employed 45 to 48 hours. We estimate the following equation: 


$$
\begin{aligned}
& E\left[N E_{82} \mid x_{81}, D_{81}\right]=x_{81} \beta+\alpha_{81}^{40} \mathrm{I}\left(D_{81}=40\right)+\alpha_{81}^{41} \mathrm{I}\left(41 \leq D_{81} \leq 43\right) \\
& +\alpha_{81}^{44} \mathrm{I}\left(D_{81}=44\right)+\alpha_{81}^{45} \mathrm{I}\left(45 \leq D_{81} \leq 48\right)
\end{aligned}
$$

\subsubsection{Results}

The results presented in this subsection are based on the 1980-1982 panel. Since our analysis uses workers employed 36 to 39 hours as a control group, we first checked that their observed characteristics were similar to those of workers employed exactly 40 hours and above. We estimated two logistic regressions where the dependent variable was "employed 40 hours" versus "employed with more than 40 hours" in years 1980 and $1981 .^{8}$ It appears that very few individual characteristics matter. More specifically, differences in education, experience or seniority are not associated with strong differences in hours category. Most differences stem from the employing firm. Short hours are not only found in the service sectors but also in some manufacturing industries, such as those producing intermediary or consumption goods. Hence, violations of our hypothesis $H_{0 A}$ are more likely to come from unobserved firm heterogeneity, that we cannot control for, than from unobserved individual heterogeneity.

The first Column of Table 3, Panel A, presents the estimates of equation (2). The independent variables that we use are: sex, region, education (4 categories), labor market experience (4 categories), seniority (4 categories), the two-digit industry of the employing firm, and information on hours worked in the entry year of the panel, i.e. 1980. The inclusion of variables on the past of the individual may render the independence assumption more plausible (Heckman, Ichimura et Todd, 1998). Finally, as mentioned above, estimates are based on a linear probability model. Resulting estimates confirm figures from Table 2: workers employed 40 hours in 1981 lose their job more often. The point estimate is equal to $2.6 \%$, significant at the level of $10 \%$, for workers employed exactly 40 hours whereas coefficients for overtime workers, i.e. employed strictly more than 40 hours, are all positive but not significantly different from zero.

\subsubsection{Working 39 Hours, 40 Hours, or More Before the Reduction}

Of course, independent of the reduction of the workweek, it is possible that workers employed exactly 40 hours or workers employed overtime lose their jobs more (respectively,. less) often than 
other workers, even after controlling for observable individual characteristics. In such a case, our preceding estimates would be biased. Table 2 shows that the job loss probability for workers employed 36 to 39 hours fluctuates from year to year, unlike workers employed exactly 40 hours. This probability is, in general, lower than the one observed for workers employed 40 hours (1979, 1980 and 1982), but it is greater in 1981. The biggest difference is observed in 1982, 3\% whereas the difference is equal to $1.4 \%$ in $1979,2.3 \%$ in 1979 , and $-1.8 \%$ in 1981 . As for workers employed overtime, they also tend to lose their jobs more often than workers employed 36 to 39 hours except in 1981; furthermore workers employed 41 to 43 hours lose their job less often than those employed exactly 40 hours. The first four Columns of Table 3, Panel A, show the probability of non-employment for our four panels, controlling for observable characteristics of the workers, expressed as a difference compared to the control group, workers employed 36 to 39 hours. No obvious pattern is present.

To identify the specific effect of the 1981 reduction of the workweek, we estimate the following double difference equation using all four panels:

$$
\begin{aligned}
E\left[N E_{t} \mid x_{t}, D_{t}, t\right]= & x_{t} \beta_{t}+\alpha_{0}^{40} \mathrm{I}\left(D_{t}=40\right)+\tilde{\alpha}_{81}^{40} \mathrm{I}\left(D_{81}=40\right)+\alpha_{0}^{41} \mathrm{I}\left(41 \leq D_{t} \leq 43\right)+\tilde{\alpha}_{81}^{41} \mathrm{I}\left(41 \leq D_{81} \leq 43\right) \\
& +\alpha_{0}^{44} \mathrm{I}\left(D_{t}=44\right)+\tilde{\alpha}_{81}^{44} \mathrm{I}\left(D_{81}=44\right)+\alpha_{0}^{45} \mathrm{I}\left(45 \leq D_{t} \leq 48\right)+\tilde{\alpha}_{81}^{45} \mathrm{I}\left(45 \leq D_{81} \leq 48\right), \\
& t=78,79,80,81
\end{aligned}
$$

The impact of the reduction of the workweek is now given by the coefficients $\tilde{\alpha}_{81}^{40}, \tilde{\alpha}_{81}^{41}, \tilde{\alpha}_{81}^{44}, \tilde{\alpha}_{81}^{45}$. The estimates of these four coefficients are presented in Table 3, Pooled Column of Panel A. For workers employed exactly 40 hours, the resulting estimate from this approach is larger, around $4 \%$, than those obtained with a simple difference method. In addition, for overtime workers, all estimated coefficients are large - some are even larger than those obtained for workers employed 40 hours as the theory predicts -- two of them are marginally significant and one strongly significant (for workers employed 45 to 48 hours). ${ }^{9}$

The double difference analysis may lead to overestimating the impact of the workweek reduction. As described in the Data Section, hours are measured from the number of hours worked in the week that precedes the interview. There is no satisfactory information on usual hours. Hence, we may capture the prevailing economic conditions rather than the specific effects of the mandatory reduction

\footnotetext{
${ }^{8}$ Those regressions are not reported here but can be found in Crépon and Kramarz (2000).

${ }^{9}$ Even though the differences between the various coefficients are not statistically significant. See also
} 
in hours. For instance, in 1981 economic conditions were bad, and workers employed 36 to 39 hours may well be those working in adversely affected firms. Therefore, such workers may lose their job more often than other types of workers. This type of measurement error results in an upward bias of the estimated impact of the reduction of the workweek, if assessed with a double difference approach.

One way of checking the validity of our control group is as follows. If workers employed 36 to 39 hours constitute a valid control group, they should not be affected by the reduction in hours. In particular, if we examine changes in hours between $t$ and $t+1$ for workers employed 36 to 39 hours at date $t$ who are also employed at date $t+1$, measured changes for $t=1981$ should not be different from changes in the years before. Of course, this is not true of workers employed 40 hours or more. Therefore, we first estimate

$$
\begin{aligned}
& E\left[\Delta D_{t}^{t+1} \mid x_{t}, D_{t}, t\right]=\quad x_{t} \beta_{t}+\tilde{\alpha}_{t}^{39} \mathrm{I}\left(36 \leq D_{t} \leq 39\right)+\alpha_{t}^{40} \mathrm{I}\left(D_{t}=40\right)+\alpha_{t}^{41} \mathrm{I}\left(41 \leq D_{t} \leq 43\right) \\
& +\alpha_{t}^{44} \mathrm{I}\left(D_{t}=44\right)+\alpha_{t}^{45} \mathrm{I}\left(45 \leq D_{t} \leq 48\right), t=78,79,80,81
\end{aligned}
$$

in which we do not include a constant. The resulting estimates are presented in the first four Columns of Table 3, Panel B. We are interested in the effects that are specific to year 1981, i.e. to changes between 1981 and 1982 that cannot be found in other years. The corresponding equation is

$$
\begin{array}{ccc}
E\left[\Delta D_{t}^{t+1} \mid x_{t}, D_{t}, t\right]= & x_{t} \beta_{t}+\tilde{\alpha}_{81}^{39} \mathrm{I}\left(36 \leq D_{81} \leq 39\right)+\alpha_{0}^{40} \mathrm{I}\left(D_{t}=40\right)+\tilde{\alpha}_{81}^{40} \mathrm{I}\left(D_{81}=40\right)+ \\
& \alpha_{0}^{41} \mathrm{I}\left(41 \leq D_{t} \leq 43\right)+\tilde{\alpha}_{81}^{41} \mathrm{I}\left(41 \leq D_{81} \leq 43\right)+\alpha_{0}^{44} \mathrm{I}\left(D_{t}=44\right)+\tilde{\alpha}_{81}^{44} \mathrm{I}\left(D_{81}=44\right) \\
& +\alpha_{0}^{45} \mathrm{I}\left(45 \leq D_{t} \leq 48\right)+\tilde{\alpha}_{81}^{45} \mathrm{I}\left(45 \leq D_{81} \leq 48\right), \quad t=78,79,80,81
\end{array}
$$

In equation (5), the reference group comprises workers employed 36 to 39 hours in the years preceding 1981. The estimates of these five coefficients, $\tilde{\alpha}_{81}^{39}, \tilde{\alpha}_{81}^{40}, \tilde{\alpha}_{81}^{41}, \tilde{\alpha}_{81}^{44}, \tilde{\alpha}_{81}^{45}$, are presented in Table 3, Panel B, Pooled Column. Consistent with our hypothesis, $\tilde{\alpha}_{81}^{39}$ is not significantly different from 0. In this regression, workers employed 36 to 39 hours in the years before 1981 constitute our reference group. Therefore, workers employed 36 to 39 hours in 1981 had hours changes that were similar to those of workers employed 36 to 39 hours in the years before 1981. Hence, their hours were not affected by the workweek reduction. We conclude that workers employed 36 to 39 hours in 1981 constitute a valid control group. In addition, workers employed 40 hours or more in 1981 saw their hours decrease. For instance, workers employed 40 hours in 1981 had a change of -0.71 hours/week (=-1.02-(-0.31)) in comparison to workers employed 36 to 39 hours in 1981. Similarly, 
workers employed 45 to 48 hours had a decrease in their hours of 1.29 hours/week. Results for workers employed 40 hours in 1981 are therefore consistent with predictions of theoretical models. However, results for overtime workers are apparently less in line with such predictions - estimated changes show a decrease instead of an increase - but the estimated changes in hours are not precise enough to give a definitive answer.

\subsubsection{Discussion}

Our first analysis has several limitations. First, the size of the control group is small -- less than $3 \%$ of the observed population - but increasing. This is obviously the main reason for the lack of precision of some of our estimates. ${ }^{10}$ Furthermore, even though it is small, this control group could also be heterogeneous. To test the robustness of our results, we estimated the same equations as those presented in Table 3 but with two different, alternative, control groups-workers employed 35 to 39 hours and workers employed 37 to 39 hours. We also estimated the same equations using data from 1975 to 1982 (instead of 1977 to 1982). All the estimated results were similar to those already discussed.

It is also possible that unobserved differences in transition rates between workers employed 36 to 39 hours and those employed 40 hours, even after controlling for all observed characteristics, still exist. In particular, we do not have pay data. The minimum wage strongly increased in July 1981 and may have generated job losses quite apart from those associated with the hours reduction. If workers employed 40 hours were more affected by the SMIC increase than those working 39 or less, we may put the blame on hours reduction whereas the job losses actually resulted from the SMIC increase. It is likely that this source of estimation bias is small. Wages are strongly correlated with skills, education, diploma, experience, or seniority. ${ }^{11}$ As mentioned previously, the introduction of all these characteristics in our regressions did not modify the estimated effects. The residual component of wages should not cause a bias.

We tried to examine the possible heterogeneity of the impact of the reduction of the workweek in the

\footnotetext{
${ }^{10}$ Nevertheless, the diffusion of the reduction of hours to workers employed 39 or less in 1981 leads to underestimating the effect of interest. In the extreme case of a complete diffusion of the reduction of the workweek to all workers employed less than 40 hours a week, we should find no effect of the hours worked in 1981 on employment losses in our regressions.

${ }^{11}$ More strongly in France than in the United States, see Abowd, Kramarz, and Margolis (1999).
} 
population. In particular, we estimated effects by skill-levels, by experience or seniority groups, and by employment status (apprentice or not). As expected, we could not isolate any significant effect. This does not mean that the reduction affects all groups similarly but, simply, that the size of the control group is too small to measure such effects.

Such limits - size of the control groups or absence of some important variables (wage or usual hours, as opposed to hours in the week preceding the interview) - motivated us to examine more carefully the situation that prevailed from 1982 onward, since these two data limitations do not exist after that date. Nevertheless, such data limitations do not invalidate the results of this first analysis: the reduction of the workweek from 40 to 39 hours is directly responsible for the increased employment to non-employment transition rates of affected workers, those who worked 40 hours as well as those who worked overtime before the reduction in 1981.

\section{Late Changes to the New Standard Workweek}

\subsection{Motivation}

A first examination of the proportion of workers employed 40 hours between 1982 and 1987, after the decree mandating the workweek reduction, confirms that the passage to 39 hours was progressive (Table 4). The fraction of workers employed exactly 40 hours became stable only in 1983, at around $20 \%$ of workers employed either 39 or 40 hours. This progressive transition to 39 hours is another potential source of identification of the effect of the workweek reduction. Examination of Table 4 also shows that differences in job loss probabilities between workers employed 39 and workers employed 40 hours exist. In 1982, this difference amounts to 1.6 points for year-to-year job losses and to 3.9 points for cumulated losses over two years. These differential losses are much greater in 1982 than in any of the following years.

The persistence of a large fraction of workers employed 40 hours (usual hours) after 1982, 20\%, demonstrates that negotiations led many firms to maintain hours as they were before 1982. Thus, a fraction of the workers declaring usual hours equal to 40 in 1982 may well work for firms that implemented the new standard before April 1982, the date of the survey, one hour being paid as overtime. The proportion of workers employed exactly 40 hours in a firm that had implemented the 39-hours workweek before April 1982 is not known, but can be estimated under various hypotheses using the proportion of workers employed 40 hours at various dates. 
Using as a parallel our first analysis, in which the control group was composed of workers employed between 36 and 39 hours in 1981, it seems that, based on the above discussion, a potential control group for this second analysis could be all workers employed 39 hours in April 1982, i.e. workers for whom the new standard was applied immediately after the publication of the February $1^{\text {st }}$ decree and who were still employed two months after this date. The associated treated group consists of all workers employed exactly 40 hours in April 1982, i.e. workers who were also employed after February $1^{\text {st }}$ in firms that had completed negotiations and kept the old standard as well as in firms that had not yet implemented the new standard. We discuss in the following subsection, the main ideas that are sufficient for this potential control/treatment comparison to detect and to measure the impact of the workweek reduction on employment. ${ }^{12}$ We discuss in the last subsection the economic validity of these hypotheses. In particular, based on a survey performed in October 1982, we show that firms that completed negotiations after April 1982 did so for reasons unrelated to their economic situation, but for reasons that were related to a weaker and less active tradition of bargaining that prevailed in their industry, whereas those that signed earlier mostly belonged to industries in which negotiations were more commonplace.

\subsection{Statistical Model}

The statistical model that we use to evaluate the effect of the reduction of the workweek is an extension to multi-wave treatments of the model used in our first analysis. Let us consider three potential states in 1983 and 1984: not affected by the reduction to 39 hours (0), affected before April 1982 (1), and affected after April 1982 (2). Let us denote $T_{0 i}, T_{1 i}, T_{2 i}$ the respective events and $N E_{i t}(0), N E_{i t}(1), N E_{i t}(2)$ is equal to 1 if individual $i$ was ever non-employed between 1982 and $\underline{t}$, for $t=1982,1983,1984$. Therefore, $N E$ summarizes the employment history of each individual in the years following the workweek reduction. Denote also $N E_{i}$ the resulting vector of labor market history at the various dates of interest. Notice that the three potential states are mutually exclusive, hence $T_{0 i}+T_{1 i}+T_{2 i}=1$. In addition, all workers being eventually affected by the reduction of the workweek, we have $T_{0 i}=0$.

Our quantities of interest are $N E_{i t}(1)-N E_{i t}(0)$ and $N E_{i t}(2)-N E_{i t}(0)$ i.e. the impact of the

\footnotetext{
${ }^{12}$ The full set of statistical hypotheses and results are contained in the Appendices of Crépon and Kramarz (2000).
} 
reduction on employment for those workers affected before April 1982 or after April 1982. However, these quantities are not directly observable. Therefore, identifying hypotheses are necessary, as they were in our first analysis, in order to recover some of the parameters of the distribution of these quantities and in order to give an evaluation of the reduction of the workweek. The basic elements of the model as well as their consequences are presented in Appendix 1. All formal details and proofs of the results are presented in Appendix 2 of Crépon and Kramarz (2000). We summarize their economic content and the resulting equations in the next paragraphs.

The first hypothesis $\left(\mathrm{H}_{\mathrm{A}}\right)$ implies that, for workers employed 40 hours in 1982, and conditionally on observable variables, the labor market state associated with being affected before April 1982, $N E_{i}(1)$, is independent of the date at which the new standard was implemented, $T_{l i}$. This is the analog of hypothesis $\mathrm{H}_{0 \mathrm{~A}}$ of our previous model. The empirical plausibility of this hypothesis is discussed in the final subsection of this section.

In addition, we assume - as hypothesis $\left(\mathrm{H}_{\mathrm{B}}\right)$ - that the effect of the reduction of the workweek is independent of the outcome, 39 or 40 hours, of the negotiation surrounding implementation of the new standard workweek. This last hypothesis is not very demanding since it amounts to neglecting the additional cost induced by one overtime hour when the outcome is 40 (overtime adds $25 \%$ to a normal hour). Notice that our first analysis tends to support this hypothesis.

Proposition 1 in Appendix 1 shows that under these hypotheses, the potential control group, i.e. workers employed 39 hours in 1982, is a valid control group for detecting an impact of the workweek reduction on employment. In particular, it implies that as soon as the reduction of the workweek has no employment effect, i.e. $N E_{i}(0)=N E_{i}(1)=N E_{i}(2)$, a regression trying to explain non-employment in 1983 or 1984 should not include an indicator for working 40 hours in 1982, denoted $1\left(D_{82 i}=40\right)$. Even if the interpretation of the resulting estimates of such an equation is complex, a significant coefficient on the variable $1\left(D_{82 i}=40\right)$ would demonstrate that the reduction had an impact on employment.

We are not only trying to detect the existence of an effect, we want to measure this effect. To do so, we need additional assumptions. First, we assume that the effects of the reduction only last a limited number of periods, specifically two years. For instance, in 1984, only workers employed in firms having completed negotiations after April 1982 are susceptible of losing their job because of the 
reduction. And, in 1983, job losses because of the reduction may come from job losses of workers employed 40 hours in 1982 (first-year effect) but also from job losses of workers employed 39 hours in 1982 (second-year effect). More precisely, consider workers employed 40 hours in 1982 with characteristics $x_{i}$. Their job loss probability between 1982 and 1983 is the sum of two components: one general to workers with characteristics $x_{i}$ and one due to the first-year effect of the reduction of the workweek, $\pi_{1}\left(x_{i}\right)$. Consider now workers employed 39 hours in 1982 with characteristics $x_{i}$. Their job loss probability is also the sum of two components: one general to workers with characteristics $x_{i}$ and one due to the second-year effect of the reduction of the workweek, $\pi_{2}\left(x_{i}\right)$. As a consequence, in 1983, the difference in job loss probabilities between workers employed 40 hours in 1982 and those employed 39 hours in 1982 (and employed 40 hours in 1981) is exactly $\pi_{1}\left(x_{i}\right)-\pi_{2}\left(x_{i}\right)$. The same reasoning applies to transitions between 1982 and 1984 and identifies $\pi_{1}\left(x_{i}\right)$.

However, $20 \%$ of the workers were employed 40 hours several years after completion of the negotiations (Table 4). This makes the comparison of workers employed 40 hours with those employed 39 more difficult and introduces a nuisance parameter in our estimating framework, the fraction of workers employed 40 hours in 1982 that completed their negotiations after April 1982.

Our Proposition 2 summarizes this discussion (see Appendix 1). ${ }^{13}$ We prove that the potential control group, i.e. workers employed 39 hours in 1982, is a valid control group for measuring the impact of the workweek reduction on employment and that:

$$
\begin{aligned}
& E\left(N E_{83 i} \mid x_{i}, D_{82 i}\right)=g_{83}\left(x_{i}\right)+P\left(T_{2 i}=1 \mid x_{i}, D_{82 i}=40\right)\left(\pi_{1}\left(x_{i}\right)-\pi_{2}\left(x_{i}\right)\right) 1\left(D_{82 i}=40\right) \\
& E\left(N E_{84 i} \mid x_{i}, D_{82 i}\right)=g_{84}\left(x_{i}\right)+P\left(T_{2 i}=1 \mid x_{i}, D_{82 i}=40\right) \pi_{1}\left(x_{i}\right) 1\left(D_{82 i}=40\right)
\end{aligned}
$$

where, as mentioned above, $\pi_{k}\left(x_{i}\right)$ denotes the change in employment loss probability that can be directly attributed to the reduction of the workweek for individuals with characteristics $x_{i}$ in the $\mathrm{k}^{\text {th }}$ period following negotiations, and $\mathrm{g}($.$) denotes any function \left(N E_{84}\right.$ is equal to 1 for a worker not employed in 1983 or in 1984 since we only consider workers employed in 1982). The total effect of the reduction is therefore equal to $\pi_{1}+\pi_{2}$. As noted above, there is a nuisance parameter,

\footnotetext{
${ }^{13}$ All hypotheses and proofs are presented in Appendix 2 of Crépon and Kramarz (2000).
} 
$P\left(T_{2 i}=1 \mid x_{i}, D_{82 i}=40\right)$, in these equations.

Our equations can be restated as the following regressions:

$$
\begin{aligned}
& E\left(N E_{83} \mid D_{82}, x_{i}\right)=x_{i} c+x_{i} \lambda 1\left(D_{82}=40\right) \\
& E\left(N E_{84} \mid D_{82}, x_{i}\right)=x_{i} d+x_{i} \mu 1\left(D_{82}=40\right)
\end{aligned}
$$

which yield parameters $\pi_{1}\left(x_{i}\right)-\pi_{2}\left(x_{i}\right)=x_{i} \lambda$ and $\pi_{1}\left(x_{i}\right)=x_{i} \mu$ for any given value of the nuisance parameter. Once again, for simplicity and transparency we estimate all models in this section using linear probability models. We examine the case of a homogeneous effect within the population and we also estimate a specific effect for low-wage workers. As in Section 5, we must also check that the effects that are found, if any, are specific to 1982. One cannot ignore the possibility that, starting after 1982, workers employed 40 hours lose their job more often than those employed 39. Indeed, a common reason - specific to these jobs but unobserved to the econometrician - could explain both 40 hours being the outcome of the negotiation and the destruction of these jobs, a destruction that would have taken place even without any mandatory hours reduction. Therefore, we also estimate the following equations: ${ }^{14}$

$$
\begin{aligned}
& E\left(N E_{t+1} \mid D_{t}, x_{i}\right)=\delta_{1} 1(t=82)+x_{i} c+x_{i} \tilde{\lambda} 1\left(D_{t}=40\right)+x_{i} \lambda 1\left(D_{82}=40\right) \\
& E\left(N E_{t+2} \mid D_{t}, x_{i}, z_{i}\right)=\delta_{2} 1(t=82)+x_{i} d+x_{i} \tilde{\mu} 1\left(D_{t}=40\right)+x_{i} \mu 1\left(D_{82}=40\right)
\end{aligned}
$$

Identification of the nuisance parameter $P\left(T_{2 i}=1 \mid x_{i}, D_{82 i}=40\right)$ is discussed at length in Crépon and Kramarz (2000). The solution adopted here assumes that the nuisance parameter is equal to 1 for all individuals. This corresponds to the following hypothesis: all workers employed in firms having implemented the workweek reduction before April 1982 actually work 39 hours after the reduction. The hypothesis implies that all firms in which a 40-hour workweek prevailed, with one hour being compensated as overtime (based on the French LFS of 1983 to 1987, such firms comprise 20\% of total employment), implemented the reduction to 39 hours after April 1982. Since the nuisance parameter lies between 0 and 1, this hypothesis provides us with a lower bound on the parameter of interest. $^{15}$

\footnotetext{
${ }^{14}$ We also estimate the year-by-year regressions: $\begin{aligned} & E\left(N E_{t+1} \mid D_{t}, x_{i}, z_{i}\right)=x_{i} c_{t}+z_{i} \lambda_{t} 1\left(D_{t}=40\right) \\ & E\left(N E_{t+2} \mid D_{t}, x_{i}, z_{i}\right)=x_{i} d_{t}+z_{i} \mu_{t} 1\left(D_{t}=40\right)\end{aligned}$
} 


\subsection{Results}

Our analysis is based on four panel data sets spanning three years each, 1982-1984, 1983-1985, 1984-1986, and 1985-1987. The regressions presented in the tables explain non-employment at date $t+1, N E_{t+1}$, given employment at date $t$, or non-employment at date $t+1$ or at date $t+2$, $N E_{t+2}$, given employment at date $t$, as functions of the number of workweek hours in year $t$. We consider only full-time employees working either 39 or 40 hours. Our additional explanatory variables are: the industry (2-digit classification), size of the employing firm, region (Ile de France or not), sex, diploma (6 categories), labor market experience (4 categories), seniority (4 categories), wage level (5 categories defined with respect to the minimum wage, the SMIC; a low-wage corresponding to wages between 0.95 and 1.10 times the SMIC), and labor market status (apprentice, on short-term contract, on long-term contract).

Table 5 presents estimation results in which the indicator function for 'usual hours $=40$ ' is directly included (Column 1). In Columns 2 and 3 we show the results when this indicator function and its interaction with a "low wage" indicator are both included. Column 4 gives the fraction of individuals employed exactly 40 hours within the population of interest. Results for the 1982-1984 panel demonstrate that those workers employed 40 hours in 1982 are more likely to lose their jobs. After one year, the effect amounts to $1.3 \%$. Based on proposition 2, this number measures the difference between the first year and the second year employment loss probabilities. The two-year effect, $2.7 \%$, is significantly different from zero. It is roughly twice the one-year effect, demonstrating that the effect is still present after one year. The total effect over the two years is equal to $4.1 \%$ (= $2 * 2.7-1.3$, see proposition 2).

For a value of the nuisance parameter equal to 1 , we estimate that the effect of the reduction of the workweek was a 4.1 percentage point increase in the probability of becoming non-employed (other values of the nuisance parameter would yield larger estimates of the impact). More importantly, for all possible values of the nuisance parameter, we always reject the null hypothesis of no impact of the reduction of the workweek on the employment to non-employment transition rates.

Table 5 also shows that, if estimated panel by panel, the coefficient of the "hours $=40$ " indicator

\footnotetext{
${ }^{15}$ Results using other values of this nuisance parameter are given in Crépon-Kramarz (2000).
} 
fluctuates across years. It is negative and close to 0 for the 1983 and 1985 panels, it is positive and close to significance for the 1984 panel. Given the standard errors, such values are not mutually incompatible. Still, they leave open the possibility that workers employed 40 hours lose their job more often than those working 39 for other reasons than the reduction of the workweek. Table 6 presents estimation results for the pooled regressions. The coefficient on the "hours=40" variable interacted with the 1982 year indicator is equal to 1.3 for the one-year effect and to 2.3 for the twoyear effect. Here again, this coefficient is significantly different from zero. Hence, we once more reject the null of no effect of the reduction of the standard workweek on employment. These latter estimates lead to slightly lower effects of the reduction of hours on employment losses than before. The total effect is equal to $3.3 \%(=2 * 2.3-1.3)$ in this case. Therefore, the effect of the reduction is also equal to $3.3 \%$. All these results are robust to the introduction of individual heterogeneity in the nuisance parameter. ${ }^{16}$

\subsection{Low-Wage Workers}

For the data collected since 1982, the size of the sample and the availability of the wage variable allow us to focus on the effects of the reduction of the workweek on various subgroups. We focus on the low-wage population, trying to isolate a specific effect of the hours reduction on this group. Results based on the 1982-1984 panel show a specific effect on the low-wage group employed 40 hours (Table 6). This effect is present in 1982 but not in 1983 nor in 1984. However, the effect on low-wage workers also shows up for 1985 (transitions from 1985 to 1987). If all panels are pooled, we observe a significant effect for the low-wage group that is specific to year 1982 in addition to the common effect. The estimated effect is equal to $7.7 \%$ after one year (and to $6.8 \%$, not significantly different from zero, after two years). From these results, we infer that the reduction first affects lowwage workers but that the rest of the population is also affected after two years. These very large transition rate differences for minimum wage workers appear to indicate that firms replaced their low-wage workers with workers from the pool of applicants, consistent with results of the theoretical model, in the year following the decree. This excess destruction and creation of jobs was entirely due to the mandatory rigidity of monthly earnings and not to the July 1981 increase in the SMIC. Indeed, the minimum wage continued to increase by $4 \%$ in 1982, 1983, and 1984. But, the effects that are discussed in Tables 5 and 6 are only present in 1982, the date at which the constraint on monthly

16 All such results are presented in Appendix 3 of Crépon and Kramarz, (2000). 
earnings stability was binding.

Having established that low-wage workers were most affected and this effect was present in the first year, 1983, but not in the second year, 1984, following the change, we next examine more formally the possibility that the effects persisted longer for high-wage workers than for low-wage workers, we tested several combinations of restrictions based on the estimation results presented in Table 6. All such tests are shown in Table 7. The first line shows the unrestricted results, one coefficient for high and low-wage workers one year and two years after the reduction of hours. Each subsequent line corresponds to a set of constraints. The test statistics for the validity of the set of constraints are given in the last three columns. After examination of the various test statistics, the results given in the penultimate line -- in which the second year effect, $\pi_{2}$, for the low-wage workers is constrained to be zero, hence the one-year and the two-year effects are equal for this category, whereas the coefficients for the high-wage workers are unrestricted -- appear to -summarize nicely the structure of our results. Notice first that the chi-square statistic for this constraint is lowest among all tested restrictions. More importantly, the estimated effect for low-wage workers is large, $8.4 \%$, and significant. On the other hand, the estimated effect for high-wage workers is only marginally significant. Finally, the last line presents estimates of the total effect of the reduction of the standard workweek, separately for low-wage and for high-wage workers, based on the previous restrictions. Effects of the reduction of the work week on employment losses are very strong for low-wage workers whereas effects for better compensated workers are only marginally significant.

\subsection{Back to the Control Group}

All the above results rely on one important assumption, derived from apparently reasonable hypotheses, workers employed 39 hours in 1982 constitute a valid control group for, first, detecting and, second, measuring the impact of the reduction of the workweek. We discuss now the potential problems of this approach.

Obviously, the biggest concern comes from the assumptions of independence, conditional on observable variables, between employment at various dates if affected before April 1982, $N E_{i}(1)$, and the date at which the reduction was implemented after, sometimes, negotiations with the personnel delegates or the unions, $T_{l i}$ (hypothesis $\left(\mathrm{H}_{\mathrm{A}}\right)$ ). Indeed, if all firms or sectors in good economic conditions implemented the new standard just before or at the date of publication of the 
decree whereas firms that implemented the new agreement later on were in worse health, the independence assumption would be violated and our estimates of the effects would all be upward biased. We believe that this situation is very unlikely. First, it is crucial to remember that all our estimates include firm-level variables, in particular the industry or the size of the firm. Furthermore, we attempted to use more detailed industry classification (3-digits) with no change in the results. So, if any such problem arises, it comes from variation within the sector. Fortunately, a survey conducted in September and October 1982 by INSEE, the French national statistical institute (Marchand, Rault, and Turpin, 1983) describes the implementation of the new standard work week in detail.

Marchand et al. first show that the new standard had not taken effect before February $1^{\text {st }}$ since only 8.4\% of workers had hours strictly below 40 hours in January 1982 (see their Table 1). Then, their survey shows the timing and the diffusion of the new workweek. "The diffusion of the agreements (on the reduction of the workweek) originated from the industries more accustomed to contractual negotiations and from the large nationalized companies to large industries such as the metal or the construction industries to the less concentrated industries in the trade or service sectors. ... Most of the sector-level agreements were extended to all firms in the sector by a decision of the Minister of Labor" (Marchand et al., page 4, our translation). Furthermore, more than $70 \%$ of firms with more than 500 employees declared that the reduction was implemented by means of a sector-level collective agreement, whereas the proportion is $50 \%$ for manufacturing firms with less than 100 employees and $33 \%$ in the service and trade sectors.

These results show that the process of implementation of the new workweek was primarily based on industry and firm-size considerations. In the early 1980s, the industry was the level at which many collectively negotiated agreements were executed. The reduction of the workweek was no exception. Note, however, that the industries recorded in the LFS do not correspond to the structure of negotiations: some industries negotiated simultaneously whereas other 4-digit industries bargained separately. In particular, these patterns were based on traditions of bargaining (see, again, Marchand et $a l$.) and not on a precise schedule vis-à-vis the reduction of the workweek. This gives us our exogenous source of random variation in the date of implementation of the new workweek, just before February $1^{\text {st }}$ or just after this date (April, the date of the survey). Hence, the evidence does support our independence hypothesis, conditional on observable variables, including the industry and the size of the employing firm (hypothesis $\left(\mathrm{H}_{\mathrm{A}}\right)$ ). 
In addition, one of our hypotheses implies that workers for whom the reduction took place before April and who were still employed at that date constitute a valid control group for our analysis i.e. the selection of the workers kept until April 1982 in firms having implemented the reduction before April is random, conditional on observables. On the firm's side, one may view the above evidence as supporting this hypothesis since the state vis-à-vis the reduction, affected before April (1) or affected after April (2), appears to be determined at some sector-level with little scope for firm-specific decisions. On the worker's side, we measure most of their individual characteristics sufficiently precisely and we included most available variables. ${ }^{17}$ In particular, we included a firm-specific seniority effect and a non-linear function of the wage, which captures much of the unobserved heterogeneity that often perturbs such analyses. Furthermore, the group of low-wage workers who appear to be the most affected by the reduction is a much less heterogeneous group than bettercompensated workers.

\section{Conclusion}

The election of François Mitterrand in 1981 ushered in a 5\% increase in the French minimum wage in July 1981 and, on February 1, 1982, a mandatory reduction of workweek hours, from 40 to 39, mandatory stability of monthly earnings for minimum wage workers, and recommendations - largely followed by firms - of stability of monthly earnings for all other workers.

Our two evaluation methods demonstrate that the effects of the reduction of the standard workweek were large. In our first analysis, the one-year effect is 3.9 percentage point increase in the probability of transitioning from employment to non-employment (difference-in-difference estimate) for workers employed 40 hours in 1981 as well for workers employed overtime at this same date. Our second analysis yields a lower bound on this difference in transition rates of 2.3 percentage points.. Our two methodologies give similar results even though the data and the assumptions are quite different. However, our estimated effect may seem large for a one-hour decrease and an associated increase in compensation costs of $2.5 \%\left(\frac{40-39}{40}\right)$. It is even larger, 8.4 percentage points, if one focuses on low-wage workers for whom the reduction in hours was associated with monthly pay rigidity. At this point, the reader must note that we measure employment losses of individuals and not job

\footnotetext{
${ }^{17}$ This is never a problem in this type of analysis since we are not estimating structural parameters of an economic model but the causal effect of a given public policy.
} 
destruction. The two-tiered wage system was shown to be a mechanism that induced firms to both hire and fire. Empirical evaluations of this phenomenon are rare. For France, Abowd, Corbel, and Kramarz (1999) have shown that French establishments that decrease employment by one in any given year do so by hiring three persons and separating four (including all within year entry and exit). Hence, by applying this ratio of 1/4 to our estimated effects, the associated net job destruction amounts to approximately $2 \%$ yielding an elasticity of employment to labor costs just below minus 1 , a number consistent with recent French evaluations (see Kramarz and Philippon, forthcoming).

Changes in the legal standard workweek led to employment losses, contrary to the initial goals of these policies. Gains in hourly productivity associated with the reduction of hours appear to have been insufficient to compensate firms for the increase in hourly pay. Furthermore, the policy was implemented at a particularly unfortunate moment. Figure 1 shows (log)-GDP for the years surrounding February 1982 for France, Germany, Italy, and Belgium (all expressed as thedifference from the level of (log)-GDP prevailing during the first quarter of 1982). In 1981, the business cycle in France differed from that of the other three countries. After Mitterrand's election, a Keynesian stimulation of the economy took place. The inflation that followed, aggravated by the increase in the SMIC followed by the reduction of the standard workweek, induced a loss of competitiveness for French firms. The result was a surge in imports. In turn, this induced restrictive policy measures in July 1982. The state of the economy was quite bad in the following years. The French recovery occurred one year after the other countries in the EC. This difficult economic context must be kept in mind to understand our estimates.

Of course, we provide no direct evidence of potential substitution effects, where affected workers would be replaced by more efficient ones. We only examine employment losses whereas our theoretical model tells us that the reduction in the standard workweek, when associated with monthly pay rigidity, induces both job destruction and creation. In addition, we do not provide direct evidence on the possible substitution of part-time workers for full-time workers. However, there is no evidence of an increase in the fraction of part-time workers around these dates. Even if employment had remained stable, given the structure of French unemployment where the fraction of long-term unemployed is very large, the employment losses that have their origin in these institutional changes must have had large negative consequences on the affected workers' incomes. In particular, the workers most affected were precisely the minimum wage workers that such policies try to 
protect. Because of the mandatory stability of their monthly compensation, the burden fell almost entirely on minimum wage workers employed exactly 40 hours in 1982 . Given this mandatory stability, the decrease in hours, and the increase in the minimum wage, the most effective cost minimization strategy was to fire some of these workers and hire new ones. Such replacements could still be paid the minimum wage rate but had monthly earnings that were based on actual hours worked. Our results show that firms did, indeed, follow this strategy.

The reader may legitimately wonder whether these conclusions apply to today's French, or more generally European, situation. Recall that French firms (with more than 20 employees) were required to reduce hours, from 39 to 35, in January 2000. Pending legislation for small firms will depend on the first evaluations of the new policy, the state of the economy, as well as political considerations. Indeed, the length, method, and moment of transition from 39 to 35 hours per week will determine how large firms, as well as smaller ones, accommodate current employees who are affected by the law. Although the 1981 changes were totally unexpected, the current process was fully anticipated. Nevertheless, low-wage workers, more precisely minimum wage workers, are most likely to be adversely affected by these changes, as their predecessors were, since their monthly earnings were not allowed to decrease, inducing a hike in their effective real hourly wage rate of $11 \%$. The extension of differential payroll tax subsidies for low-wage workers may well counteract the potentially major disemployment effects of this law. But, the new law may also counteract the beneficial effects on low-wage labor demand due to recent payroll tax changes, as described in Kramarz and Philippon (forthcoming), that provided more employment incentives by allowing an $18 \%$ decrease in employer-paid social contributions for workers paid the SMIC. ${ }^{18}$

\footnotetext{
${ }^{18}$ In 1996, employer-paid contributions - health insurance, pensions,...- decreased from roughly $40 \%$ of the wage to $20 \%$ of the wage.
} 


\section{References}

Abowd J. M., Kramarz F., Lemieux T., and D. N. Margolis (1999), "Minimum Wage and Youth Employment in France and the United States," in Youth Employment and the Labor Market, D. Blanchflower and R. Freeman eds., University of Chicago Press, 427-472.

Abowd J. M., Kramarz F., Margolis D. N., and T. Philippon (2000), "The Tail of Two Countries: Minimum Wage and Employment in France and the United States," IZA working paper, 203.

Abowd J. M., Kramarz F., and D. N. Margolis (1999), "High-Wage Workers and High-wage Firms," Econometrica, 67, 2, 251-333.

Andrews M.J., Schank T., and R. Simmons (1999), "Does Work-Sharing Work? Some empirical evidence from the IAB panel," paper presented at the SOLE-EALE meetings, Milan.

Brodaty T., Crépon B., and D. Fougère (1999), "Using Matching Estimators to Evaluate Alternative Youth Employment Programmes : Evidence from France 1986-1988,” CREST mimeo.

Calmfors L., and M. Hoel (1988), "Work Sharing and Overtime," Scandinavian Journal of Economics, 90, 1, 45-62.

Card D., Kramarz F., and T. Lemieux (1999), "Changes in the Relative Structure of Wages and Employment : a Comparison of the United States, Canada, and France," Canadian Journal of Economics, 32, 843-877.

Ehrenberg R. G. (1971), "Heterogeneous Labor, the Internal Labor Market, and the Dynamics of the Employment-Hours Decision,” Journal of Economic Theory, 3, 85-104.

Heckman J., Ichimura H., and P. Todd (1998), “Characterizing Selection Bias Using Experimental Data," Econometrica, 66, 5, 1017-1098.

Heckman J., Lalonde R.J., and J. Smith (1999), “The Economics and Econometrics of Active Labor Market Programs," in Ashenfelter and Card eds., Handbook of Labor Economics, NorthHolland, Vol. 3A, 1865-2097. 
Hunt J. (1999), "Has Work-Sharing Worked in Germany," Quarterly Journal of Economics, February, 117-148.

Imbens G. (1999), “The Role of the Propensity Score in Estimating Dose-Response Functions," UCLA mimeo.

Kramarz F. and T. Philippon (forthcoming), "The Impact of Differential Payroll Tax Subsidies on Minimum Wage Employment," Journal of Public Economics.

Lechner M. (1999), "Identification and Estimation of Causal Effects of Multiple Treatments Under the Conditional Independence Assumption," University of St. Gallen mimeo.

Marchand O., D. Rault and E. Turpin (1983), “Des 40 heures aux 39 heures: processus et réactions des entreprises," Economie et Statistique, $\mathrm{n}^{\circ} 154$.

Rosen S. (1969), "Short-Run Employment Variation on Class-I Railroads in the U.S., 1947-1963," Econometrica, 36, 511-529.

Rubin D.B. (1974), "Estimating Causal Effects of Treatments in Randomized and Nonrandomized Studies," Journal of Educational Psychology, 66, 688-701.

Rubin D.B. (1977), “Assignment to Treatment Group on the Basis of a Covariate," Journal of Educational Statistics, 2, 1-26.

The Economist (1981), “An ill wind that won't necessarily blow Giscard out,” January 10.

The Economist (1998a), "The Working Week, Fewer Hours, More Jobs,” April 4.

The Economist (1998b), “Things Undone,” October 31.

The Economist (1998c), “BMW's British Bruises,” December 5.

The Economist (1999a), “Could be Worse,” February 6.

Trejo S.J. (1991), “The Effects of Overtime Pay Regulation on Worker Compensation,” American Economic Review, 81,4, 719-740. 
Table 1: Hours Worked, 1976-1981

\begin{tabular}{|r|cccccc|}
\hline Fraction of Employment Working: & 1976 & 1977 & 1978 & 1979 & 1980 & 1981 \\
\hline & & & & & & \\
36 to 39 Hours & 2.2 & 2.1 & 2.5 & 2.4 & 2.6 & 2.4 \\
40 Hours & 46.6 & 53.6 & 55.6 & 58.6 & 60.9 & 65.9 \\
41 to 43 Hours & 18.8 & 18.8 & 19.5 & 19.3 & 17.5 & 15.2 \\
44 Hours & 4.2 & 4.4 & 3.9 & 2.3 & 2.7 & 2.0 \\
45 to 48 Hours & 28.2 & 21.1 & 18.6 & 17.4 & 16.4 & 14.5 \\
Number of Observations: & 5,422 & 6,133 & 6,212 & 6,123 & 6,409 & 6,509 \\
\hline
\end{tabular}

Notes: Labor Force Survey, 1976 to 1981.

Table 2: Employment Losses, by Work Hours

\begin{tabular}{|c|c|c|c|c|c|}
\hline \multirow{2}{*}{\multicolumn{2}{|c|}{\begin{tabular}{|l|} 
Panel $t$ to $t+2$ \\
Job Losses of Workers
\end{tabular}}} & $80-82$ & $77-79$ & $78-80$ & $79-81$ \\
\hline & & & & & \\
\hline \multirow[t]{6}{*}{ Employed: } & 36 to 39 Hours & 3.2 & 3.9 & 2.7 & 7.3 \\
\hline & 40 Hours & 6.2 & 4.3 & 5.0 & 5.5 \\
\hline & 41 to 43 Hours & 4.6 & 3.1 & 3.6 & 4.0 \\
\hline & 44 Hours & 6.0 & 5.0 & 2.1 & 5.8 \\
\hline & 45 to 48 Hours & 5.7 & 4.0 & 4.0 & 3.0 \\
\hline & Number of Observations: & 6,509 & 6,212 & 6,123 & 6,409 \\
\hline
\end{tabular}

Notes: Labor Force Survey, 1977-1982. 
Table 3: Non-Employment and Changes in Hours for Workers Employed in Year $t+1$

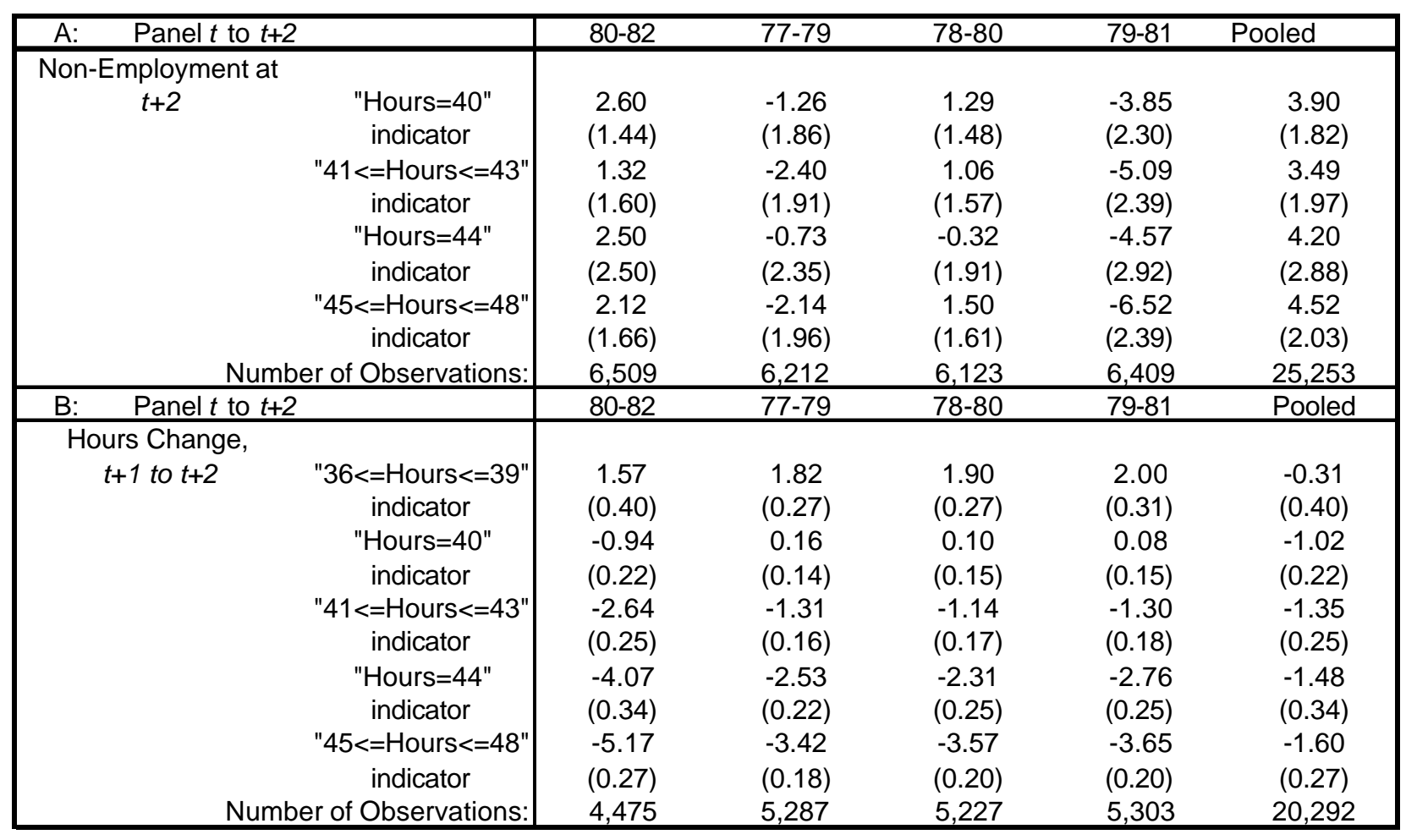

Notes: Regressions for the LFS panels of 77-79, 78-80, 79-81, and 80-82 (linear probability models for panel A, OLS for panel B). The dependent variable is non-employment in the exit year of the panel $(79,80,81$, and 82 , respectively) for panel $\mathrm{A}$, the change in hours between median year (78, 79, 80, and 81, respectively) and exit year $(79,80,81$, and 82 , respectively) for panel $\mathrm{B}$. Independent variables: indicator for the "hours" categories (only reported coefficients), ndustry, region (Ile de France or other), skill-level (3 categories), sex, diploma (6 categories), experience (4 categories), seniority (4 categories), labor market status (apprentice or not), and "hours in first year of the panel strictly below 40" and "hours in first year of the panel strictly above 40". The population includes all full-time workers in the private sector working between 36 and 48 hours in the median year of each panel $(78,79,80$, and 81, respectively). Column 1 reports estimates for the panel 8082, Columns 2, 3, and 4 report estimates for the panels 77-79, 78-80, and 79-81 respectively. Column 5 reports pooled estimates where all variables are interacted with the relevant year indicator except for the "hours" categories for which we introduce pooled coefficients and coefficient specific to year 1981 (panel 80-82). These last coefficients are those reported in the Column 5 (pooled).

Robust standard errors are given between parentheses. 
Table 4: Employment to Non-Employment Transitions for Workers Employed 39 or 40 Hours in 1982, 1983, 1984, and 1985

\begin{tabular}{|c|c|c|c|c|c|}
\hline & & \multicolumn{3}{|c|}{$\begin{array}{c}\text { Employment Losses Cumulated } \\
\text { Over }\end{array}$} & \multirow{2}{*}{$\begin{array}{c}\text { Number of } \\
\text { Observations }\end{array}$} \\
\hline & & Proportion & One year & Two years & \\
\hline \multirow{3}{*}{82} & 40 hours & 27.9 & 8.2 & 16.5 & 1,700 \\
\hline & 39 hours & 72.1 & 6.6 & 12.6 & 4,397 \\
\hline & Difference & & 1.6 & 3.9 & \\
\hline \multirow{3}{*}{83} & 40 hours & 21.9 & 6.9 & 12.6 & 1,214 \\
\hline & 39 hours & 78.1 & 6.4 & 11.8 & 4,331 \\
\hline & Difference & & 0.5 & 0.8 & \\
\hline \multirow{3}{*}{84} & 40 hours & 20.3 & 7.9 & 14.8 & 1,112 \\
\hline & 39 hours & 79.7 & 6.6 & 11.9 & 4,371 \\
\hline & Difference & & 1.3 & 2.9 & \\
\hline \multirow{3}{*}{85} & 40 hours & 19.1 & 5.7 & 11.9 & 996 \\
\hline & 39 hours & 80.9 & 6.3 & 12.1 & 4,225 \\
\hline & Difference & & -0.6 & -0.2 & \\
\hline
\end{tabular}

Notes: LFS panels for years 82-84, 83-85, 84-86 and 85-87. Statistics computed using the nonemployment variables in the median and in the final year of each panel. Observations: All full-time workers employed 39 or 40 hours in the first year of the panel. 
Table 5: Job Losses and Hours Worked: Late Reduction

Total Effects and Effect for Low-Wage Workers

Panel by Panel Estimation

\begin{tabular}{|c|c|c|c|}
\hline Period & $\begin{array}{l}\text { "hours=40" } \\
\text { indicator }\end{array}$ & $\begin{array}{l}\text { "hours=40" } \\
\text { indicator }\end{array}$ & $\begin{array}{c}\text { "hours=40" } \\
\text { and } \\
\text { low-wage } \\
\text { indicator } \\
\end{array}$ \\
\hline $\begin{array}{c}82-84 \\
\mathrm{NE}_{83}\end{array}$ & $\begin{array}{c}1.28 \\
(0.77)\end{array}$ & $\begin{array}{c}0.53 \\
(0.77)\end{array}$ & $\begin{array}{c}8.49 \\
(3.66)\end{array}$ \\
\hline $\begin{array}{c}82-84 \\
\mathrm{NE}_{84} \\
\end{array}$ & $\begin{array}{c}2.71 \\
(1.02) \\
\end{array}$ & $\begin{array}{c}1.75 \\
(1.04) \\
\end{array}$ & $\begin{array}{l}10.87 \\
(4.50) \\
\end{array}$ \\
\hline $\begin{array}{c}82-84 \\
2 \mathrm{NE}_{84}-\mathrm{NE}_{83} \\
\end{array}$ & $\begin{array}{c}4.13 \\
(1.63) \\
\end{array}$ & $\begin{array}{c}2.96 \\
(1.66) \\
\end{array}$ & $\begin{array}{l}13.24 \\
(7.09) \\
\end{array}$ \\
\hline $\begin{array}{c}83-85 \\
\mathrm{NE}_{84}\end{array}$ & $\begin{array}{l}-0.08 \\
(0.81)\end{array}$ & $\begin{array}{l}-0.06 \\
(0.79)\end{array}$ & $\begin{array}{l}-0.14 \\
(3.02)\end{array}$ \\
\hline $\begin{array}{c}83-85 \\
\mathrm{NE}_{85}\end{array}$ & $\begin{array}{l}-0.36 \\
(1.04)\end{array}$ & $\begin{array}{l}-0.53 \\
(1.05)\end{array}$ & $\begin{array}{c}1.21 \\
(3.72)\end{array}$ \\
\hline $\begin{array}{c}83-85 \\
2 \mathrm{NE}_{85}-\mathrm{NE}_{84} \\
\end{array}$ & $\begin{array}{l}-0.64 \\
(1.62) \\
\end{array}$ & $\begin{array}{l}-1.01 \\
(1.66) \\
\end{array}$ & $\begin{array}{c}2.56 \\
(5.70) \\
\end{array}$ \\
\hline $\begin{array}{c}84-86 \\
\mathrm{NE}_{85} \\
\end{array}$ & $\begin{array}{c}0.91 \\
(0.89) \\
\end{array}$ & $\begin{array}{c}0.93 \\
(0.90) \\
\end{array}$ & $\begin{array}{l}-0.38 \\
(3.98) \\
\end{array}$ \\
\hline $\begin{array}{c}84-86 \\
\mathrm{NE}_{86}\end{array}$ & $\begin{array}{c}2.05 \\
(1.16)\end{array}$ & $\begin{array}{c}1.81 \\
(1.18)\end{array}$ & $\begin{array}{r}2.94 \\
(5.22) \\
\end{array}$ \\
\hline $\begin{array}{c}84-86 \\
2 \mathrm{NE}_{86}-\mathrm{NE}_{85} \\
\end{array}$ & $\begin{array}{c}3.20 \\
(1.82) \\
\end{array}$ & $\begin{array}{c}2.68 \\
(1.84) \\
\end{array}$ & $\begin{array}{c}6.28 \\
(8.32) \\
\end{array}$ \\
\hline $\begin{array}{c}85-87 \\
\mathrm{NE}_{86} \\
\end{array}$ & $\begin{array}{l}-0.94 \\
(0.85) \\
\end{array}$ & $\begin{array}{l}-1.38 \\
(0.82) \\
\end{array}$ & $\begin{array}{c}3.30 \\
(3.42) \\
\end{array}$ \\
\hline $\begin{array}{c}85-87 \\
\mathrm{NE}_{87} \\
\end{array}$ & $\begin{array}{l}-0.53 \\
(1.15) \\
\end{array}$ & $\begin{array}{l}-1.80 \\
(1.14) \\
\end{array}$ & $\begin{array}{r}9.48 \\
(4.34) \\
\end{array}$ \\
\hline $\begin{array}{c}85-87 \\
2 \mathrm{NE}_{87}-\mathrm{NE}_{86}\end{array}$ & $\begin{array}{l}-0.12 \\
(1.83) \\
\end{array}$ & $\begin{array}{l}-2.21 \\
(1.84) \\
\end{array}$ & $\begin{array}{r}15.66 \\
(6.81) \\
\end{array}$ \\
\hline
\end{tabular}

Notes: Panel by panel regressions (linear probability models). The dependent variable is employment loss in the median year or in the last year of the panel. Independent variables: industry, region (Ile de France or other), skill-level (3 categories), sex, diploma (6 categories), experience (4 categories), seniority (4 categories), labor market status (apprentice, short-term contract, or long-term-contract), wage level (5 categories defined with respeoct to the minimum wage in the relevant year), and indicator for "hours $=40$ " (only reported coefficient in column 1), indicator for "hours $=40$ " and its interaction with an indicator for a low-wage worker, i.e. with wage between 0.95 and 1.1 times the minimum wage (both are the only reported coefficients in column 2). Observations Full-time workers of the private sector employed either 39 or 40 hours in the entry year of the panel. Robust standard errors in parentheses. 
Table 6: Job Losses and Hours Worked : Late Reduction.

Total Effects and Effect for Low-Wage Workers.

Pooled Estimates

\begin{tabular}{|c|cc|cccc|}
\hline Period & $\begin{array}{c}\text { hours=40 } \\
\text { indicator }\end{array}$ & $\begin{array}{c}\text { Hours=40 } \\
\text { and } \\
\text { Year=82 } \\
\text { indicator }\end{array}$ & $\begin{array}{c}\text { hours=40 } \\
\text { indicator }\end{array}$ & $\begin{array}{c}\text { Hours=40 } \\
\text { and } \\
\text { Low- } \\
\text { wage } \\
\text { indicator }\end{array}$ & $\begin{array}{c}\text { Hours=40 } \\
\text { and } \\
\text { Year=82 } \\
\text { indicator }\end{array}$ & $\begin{array}{c}\text { Hours=40, } \\
\text { Low-wage, } \\
\text { and } \\
\text { Year=82 } \\
\text { indicator }\end{array}$ \\
\hline \hline $\mathrm{NE}_{\mathrm{t}+1}$ & 0.00 & 1.29 & -0.10 & 0.79 & 0.64 & 7.70 \\
& $(0.49)$ & $(0.91)$ & $(0.49)$ & $(1.97)$ & $(0.91)$ & $(4.14)$ \\
\hline $\mathrm{NE}_{\mathrm{t}+2}$ & 0.40 & 2.30 & -0.10 & 4.06 & 1.84 & 6.80 \\
& $(2.04)$ & $(1.20)$ & $(0.49)$ & $(2.49)$ & $(1.22)$ & $(5.15)$ \\
\hline Number of Observations & \multicolumn{7}{|c|}{22,345} \\
\hline
\end{tabular}

Notes : Pooled regressions (linear probability models). The dependent variable isemployment loss in the median year or in the last year of each panel. Independent variables: industry, region (Ile de France or other), skill-level (3 categories), sex, diploma (6 categories), experience (4 categories), seniority (4 categories), labor market status (apprentice, short-term contract, or long-term-contract), wage level (5 categories defined with respect to the minimum wage in the relevant year), and an indicator for "hours=40" and its interaction with a year indicator for 1982 (both are the only reported coefficients in column 1), an indicator for "hours=40," its interaction with a year indicator for 1982, an indicator for "hours $=40$ " interacted with an indicator for a low-wage worker, i.e. with wage between 0.95 and 1.1 times the minimum wage, and its interaction with a year indicator for 1982 (all four are the only reported coefficients in column 2). Robust standard errors in parentheses. 
Table 7: Summary and Tests of Possible Effects and Constraints

\begin{tabular}{|c|c|c|c|c|c|c|c|}
\hline & $\begin{array}{l}\text { One-year } \\
\text { Effect } \\
\text { (Low- } \\
\text { wage) }\end{array}$ & $\begin{array}{c}\text { One-year } \\
\text { Effect } \\
\text { (High- } \\
\text { wage) }\end{array}$ & $\begin{array}{c}\text { Two-year } \\
\text { Effect } \\
\text { (Low- } \\
\text { wage) }\end{array}$ & $\begin{array}{c}\text { Two-year } \\
\text { Effect } \\
\text { (High- } \\
\text { wage) }\end{array}$ & $\begin{array}{l}\text { Degrees of } \\
\text { Freedom } \\
\text { (d) }\end{array}$ & $\begin{array}{c}\text { Test } \\
\text { statistics } \\
\chi^{2}(\mathrm{~d})\end{array}$ & p-value \\
\hline Unconstrained & $\begin{array}{c}8.34 \\
(4.06) \\
\end{array}$ & $\begin{array}{c}0.64 \\
(0.91) \\
\end{array}$ & $\begin{array}{r}8.64 \\
(5.00) \\
\end{array}$ & $\begin{array}{c}1.84 \\
(1.22) \\
\end{array}$ & - & - & - \\
\hline \multicolumn{8}{|l|}{ Constrained: } \\
\hline $\begin{array}{c}\text { Low-wage } \\
\text { effects } \\
= \\
\text { High-wage } \\
\text { effects }\end{array}$ & \multicolumn{2}{|c|}{$\begin{array}{c}0.99 \\
(0.88)\end{array}$} & \multicolumn{2}{|c|}{$\begin{array}{c}2.18 \\
(1.19)\end{array}$} & 2 & 3.45 & 0.18 \\
\hline $\begin{array}{c}\text { 1-year effects } \\
= \\
\text { 2-year effects }\end{array}$ & $\begin{array}{c}8.40 \\
(3.99)\end{array}$ & $\begin{array}{c}0.75 \\
(0.90)\end{array}$ & $\begin{array}{c}8.40 \\
(3.99)\end{array}$ & $\begin{array}{c}0.75 \\
(0.90)\end{array}$ & 2 & 1.78 & 0.41 \\
\hline $\begin{array}{c}\text { 1-year effects } \\
= \\
0\end{array}$ & 0 & 0 & $\begin{array}{c}1.69 \\
(3.69)\end{array}$ & $\begin{array}{c}1.25 \\
(0.90)\end{array}$ & 2 & 4.68 & 0.10 \\
\hline $\begin{array}{c}\text { 1-year effects } \\
\text { High-wage } \\
= \\
0\end{array}$ & $\begin{array}{c}8.31 \\
(4.06)\end{array}$ & 0 & $\begin{array}{c}8.62 \\
(5.00)\end{array}$ & $\begin{array}{c}1.25 \\
(0.90)\end{array}$ & 1 & 0.49 & 0.48 \\
\hline $\begin{array}{c}\text { 1-year=0 } \\
\text { (High-wage) } \\
\text { and } \\
\text { 1-year=2-year } \\
\text { (Low-wage) }\end{array}$ & $\begin{array}{c}8.37 \\
(3.99)\end{array}$ & 0 & $\begin{array}{c}8.37 \\
(3.99)\end{array}$ & $\begin{array}{c}1.25 \\
(0.90)\end{array}$ & 2 & 0.50 & 0.78 \\
\hline $\begin{array}{l}\text { 1-year effects } \\
\qquad= \\
\text { 2-year effects } \\
\text { for Low-wage }\end{array}$ & $\begin{array}{c}8.40 \\
(3.99)\end{array}$ & $\begin{array}{c}0.64 \\
(0.91)\end{array}$ & $\begin{array}{c}8.40 \\
(3.99)\end{array}$ & $\begin{array}{c}1.84 \\
(1.22)\end{array}$ & 1 & 0.006 & 0.94 \\
\hline $\begin{array}{c}\text { Total effects: } \\
\text { If }\end{array}$ & \multicolumn{2}{|c|}{$\pi_{1}+\pi_{2}$ (Low-wage) } & \multicolumn{2}{|c|}{$\pi_{1}+\pi_{2}$ (High-wage) } & & & \\
\hline $\begin{array}{l}\text { 1-year effects } \\
\qquad= \\
\text { 2-year effects } \\
\text { for Low-wage }\end{array}$ & \multicolumn{2}{|c|}{$\begin{array}{c}8.40 \\
(3.99)\end{array}$} & \multicolumn{2}{|c|}{$\begin{array}{c}3.03 \\
(1.94)\end{array}$} & \multicolumn{3}{|c|}{-} \\
\hline
\end{tabular}

Notes: All computations are based on Table 6 results. The last three columns present the basis for the test of the restrictions given in the corresponding line. 


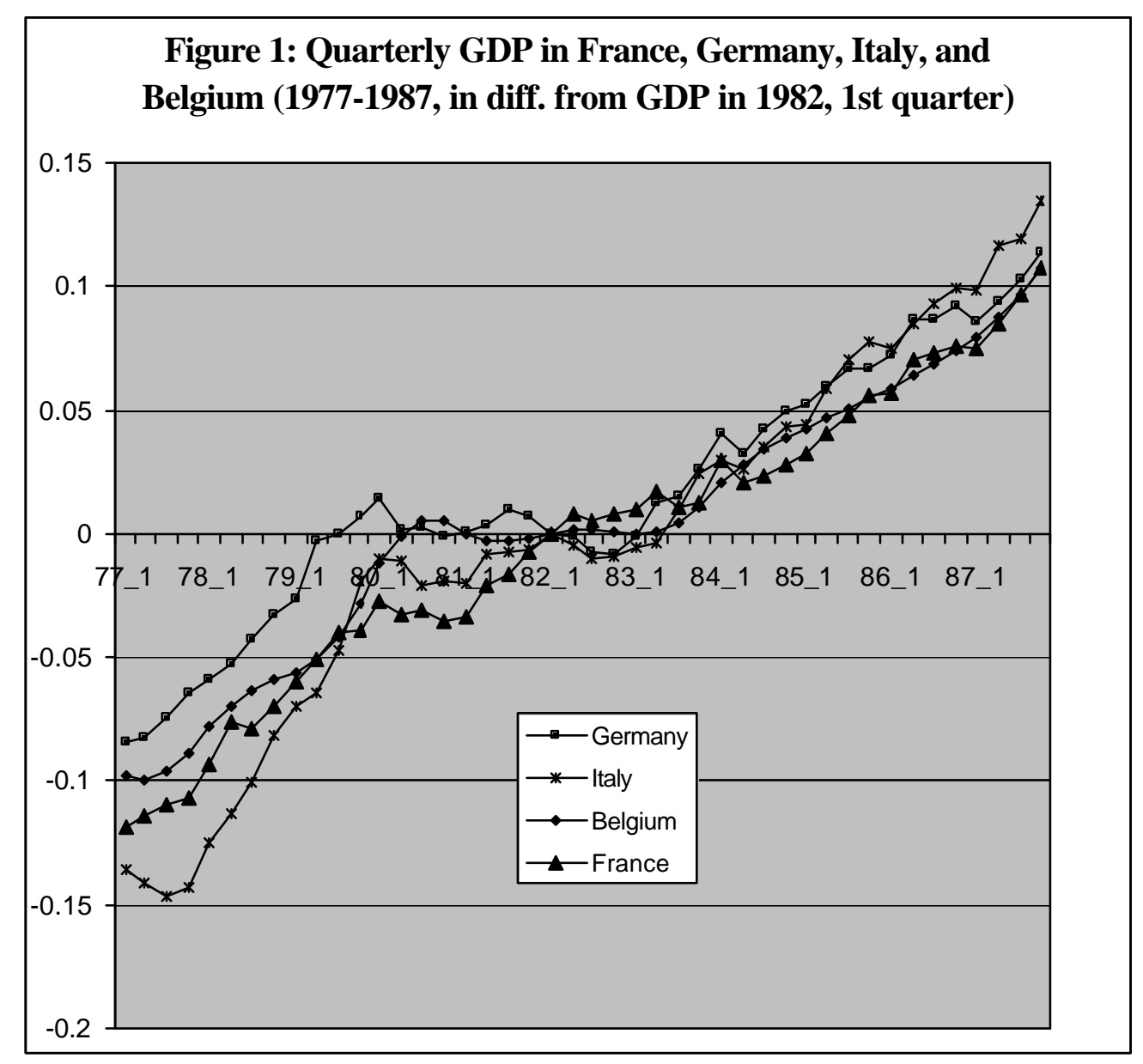

Sources: OECD for Germany, Italy, and Belgium. Quarterly accounts for France. 


\section{Appendix 1}

We first present our hypotheses. The first hypothesis $\left(\mathrm{H}_{\mathrm{A}}\right)$ is the following:

$$
H_{A}: E\left(N E_{i}(1) \mid x_{i}, D_{82 i}=40, N E_{82 i}(1)=0, T_{2 i}=1\right)=E\left(N E_{i}(1) \mid x_{i}, D_{82 i}=40, N E_{82 i}(1)=0, T_{1 i}=1\right)
$$

$\left(\mathrm{H}_{\mathrm{A}}\right)$ implies that, for workers employed 40 hours in 1982, and conditionally on observable variables, the labor market state associated to being affected before April 1982, $N E_{i}(1)$, is independent of the date at which the new standard was implemented, $T_{l i}$.

In addition, we assume - hypothesis $\left(\mathrm{H}_{\mathrm{B}}\right)$ - that the effect of the reduction of the workweek is independent of the outcome, 39 or 40 hours, of the negotiation surrounding implementation of the new standard workweek. Under these two hypotheses, the conditional expectation of $N E_{i}$ is:

$$
\begin{aligned}
& E\left(N E_{i} \mid x_{i}, D_{82 i}, N E_{82 i}=0\right)=E\left(N E_{i}(1) \mid x_{i}, D_{82 i}=39, N E_{82 i}(1)=0, T_{1 i}=1\right)+ \\
& {\left[E\left(N E_{i}(2) \mid x_{i}, D_{82 i}=40, N E_{82 i}(2)=0, T_{2 i}=1\right)-E\left(N E_{i}(1) \mid x_{i}, D_{82 i}=40, N E_{82 i}(1)=0, T_{2 i}=1\right)\right](\text { A. } 1)} \\
& P\left(T_{2 i}=1 \mid x_{i}, D_{82 i}=40, N E_{82 i}=0\right) 1\left(D_{82 i}=40\right)
\end{aligned}
$$

The following proposition shows that under these hypotheses, the potential control group, i.e. workers employed 39 hours in 1982, is a valid control group for detecting an impact of the workweek reduction on employment:

Proposition 1: Under hypotheses $H_{A}$ and $H_{B}$, when the reduction of the workweek has no effect on the labor market state:

$$
N E_{i t}(0)=N E_{i t}(1)=N E_{i t}(2), \forall i, \text { and } \forall t, t=1982,1983,1984
$$

then the following testable restriction holds:

$$
E\left(N E_{i} \mid x_{i}, D_{82 i}, N E_{82 i}=0\right)=E\left(N E_{i} \mid x_{i}, N E_{82 i}=0\right)
$$

Proof : see Appendix 2 of Crépon and Kramarz (2000).

Therefore, equation (A.1) should not include the term $1\left(D_{82 i}=40\right)$ as soon as the reduction of the workweek has no employment effect, i.e. $N E_{i}(0)=N E_{i}(1)=N E_{i}(2)$.

To measure the effect of the reduction, we first note that equation (5) includes a vector of parameters of the joint distribution of potential outcomes:

$$
\left.\frac{E\left(N E_{i}(2) \mid x_{i}, D_{82 i}=40, N E_{82 i}(2)=0, T_{2 i}\right.}{2}=1\right)-E\left(N E_{i}(1) \mid x_{i}, D_{82 i}=40, N E_{82 i}(1)=0, T_{2 i}=1\right)
$$

which measures the difference between the effect of the reduction when implemented after April 1982 - state (2) - and what would have been the effect had the reduction been implemented before April 1982 - state (1) - and had workers not lost employment between 1981 and 1982, evaluated for individuals for whom the reduction actually took place after April 1982. Equation (5) also includes a nuisance parameter $P\left(T_{2}=1 \mid x_{i}, D_{82}=40\right)$.

To go from the above parameters to our parameters of interest,

$$
\begin{aligned}
& \pi_{1}\left(x_{i}\right)=E\left(N E_{83 i}(2)-N E_{83 i}(0) \mid x_{i}, D_{82 i}=40, N E_{82 i}(2)=0, T_{2 i}=1\right) \\
& \pi_{2}\left(x_{i}\right)=E\left(N E_{84 i}(2)-N E_{84 i}(0) \mid x_{i}, D_{82 i}=40, N E_{83 i}(2)=0, T_{2 i}=1\right)
\end{aligned}
$$

we assume that these effects only last a limited number of periods, two years in our empirical application. Together with two other technical hypotheses (these three hypotheses, denoted $\mathrm{H}_{C}, \mathrm{H}_{\mathrm{D}}$, $\mathrm{H}_{\mathrm{E}}$, are presented in Appendix 2 of Crépon and Kramarz, 2000), we are able to recover the parameters of interest of our analysis, $\pi_{1}\left(x_{i}\right)$ and $\pi_{2}\left(x_{i}\right)$.

The following proposition shows that under these hypotheses, the potential control group, i.e. workers employed 39 hours in 1982, is a valid control group for measuring the impact of the workweek 
reduction on employment:

Proposition 2: Under hypotheses $H_{A}$ to $H_{E}$, employment to non-employment transitions between 1982 and 1983, and between 1982 and 1984 follow:

$E\left(N E_{83 i}(2) \mid x_{i}, N E_{82 i}(2)=0, T_{2 i}=1\right)-E\left(N E_{83 i}(1) \mid x_{i}, N E_{82 i}(1)=0, T_{2 i}=1\right)=\pi_{1}\left(x_{i}\right)-\pi_{2}\left(x_{i}\right)$

$E\left(N E_{84 i}(2) \mid x_{i}, N E_{82 i}(2)=0, T_{2 i}=1\right)-E\left(N E_{84 i}(1) \mid x_{i}, N E_{82 i}(1)=0, T_{2 i}=1\right)=\pi_{1}\left(x_{i}\right)$

Therefore,

$E\left(N E_{83 i} \mid x_{i}, D_{82 i}\right)=g_{83}\left(x_{i}\right)+P\left(T_{2 i}=1 \mid x_{i}, D_{82 i}=40\right)\left(\pi_{1}\left(x_{i}\right)-\pi_{2}\left(x_{i}\right)\right) 1\left(D_{82 i}=40\right)$

$E\left(N E_{84 i} \mid x_{i}, D_{82 i}\right)=g_{84}\left(x_{i}\right)+P\left(T_{2 i}=1 \mid x_{i}, D_{82 i}=40\right) \pi_{1}\left(x_{i}\right) 1\left(D_{82 i}=40\right)$

where $\pi_{k}\left(x_{i}\right)$ denotes the change in employment loss probability that can be directly attributed to the reduction of the workweek for individuals with characteristics $x_{i}$ in the $k^{\text {th }}$ period following negotiations, and where g(.) denotes any function ( $\mathrm{NE}_{84}$ is equal to 1 for a worker not employed in 1983 or in 1984 since we only consider workers employed in 1982). The total effect is $\pi_{1}+\pi_{2}$.

Proof : see Appendix 2 of Crépon and Kramarz (2000).

Remark: If the impact lasts one year instead of two, we have $\pi_{2}=0$, a testable restriction. 


\section{IZA Discussion Papers}

$\begin{array}{ll}\text { No. } & \text { Author(s) } \\ & \\ 401 & \text { J. Boone } \\ & \text { P. Fredriksson } \\ & \text { B. Holmlund } \\ & \text { J. C. van Ours }\end{array}$

402

O. Ashenfelter

D. Card

403

404

H. Battu

C. R. Belfield

P. J. Sloane

405

406

407

408

409

410

411

412

M. Barbie

$413 \quad$ H. Bonin
M. Hagedorn

A. Kaul

R. Euwals

H. N. Mocan

E. Tekin

P. Apps

R. Rees

H. Lehmann

J. Wadsworth

S. Stillman

A. Frederiksen

N. Westergaard-

Nielsen

M. Bertrand

F. Kramarz

B. Crépon

F. Kramarz
Title

Area

Date

Optimal Unemployment Insurance with

3

$11 / 01$

Monitoring and Sanctions

Did the Elimination of Mandatory Retirement

5

$11 / 01$

Affect Faculty Retirement Flows?

How Do Layoff Costs Affect Employment?

$11 / 01$

Human Capital Spill-Overs Within the Workplace

$11 / 01$

Testing for the Option Value of Migration

$11 / 01$

Labor Market Flows and Equilibrium Search

Unemployment

Education Driving the Rise in Dutch Female

Employment: Explanations for the Increase in

Part-time Work and Female Employment in the

Netherlands; Contrasted with Germany

Nonprofit Sector and Part-Time Work: An

$12 / 01$

Analysis of Employer-Employee Matched Data

of Child Care Workers

Fertility, Female Labor Supply and Public Policy

6

$12 / 01$

Wage Arrears and the Distribution of Earnings in 4

$12 / 01$

Russia

The Response of Consumption in Russian

4

$12 / 01$

Households to Economic Shocks

Government Debt as Insurance against

7

$12 / 01$

Macroeconomic Risk

Participation Behavior of East German Women

1

$12 / 01$

after German Unification

Where Did They Go?

$01 / 02$

Does Entry Regulation Hinder Job Creation?

6

Evidence from the French Retail Industry

Employed 40 Hours or Not-Employed 39:

6

$01 / 02$

the Workweek 